\title{
Dectin-1 Positive Dendritic Cells Expand after Infection with Leishmania major Parasites and Represent Promising Targets for Vaccine Development
}

OPEN ACCESS

Edited by:

Abhay Satoskar,

The Ohio State University,

United States

Reviewed by:

Reto Guler,

University of Cape Town,

South Africa

Peter Epeh Kima,

University of Florida,

United States

*Correspondence:

Uwe Ritter

uwe.ritter@ukr.de

${ }^{\dagger}$ Present address:

Anne Rascle,

Lophius Biosciences GmbH,

Regensburg, Germany

Specialty section:

This article was submitted to Microbial Immunology,

a section of the journal

Frontiers in Immunology

Received: 05 October 2017

Accepted: 30 January 2018

Published: 26 February 2018

Citation:

Zimara N, Chanyalew M, Aseffa A, van Zandbergen $G$, Lepenies $B$, Schmid M, Weiss R, Rascle A, Wege AK, Jantsch J, Schatz V, Brown GD and Ritter U (2018) Dectin-1 Positive Dendritic Cells

Expand after Infection with Leishmania major Parasites and Represent Promising Targets for

Vaccine Development.

Front. Immunol. 9:263.

doi: 10.3389/fimmu.2018.00263
Nicole Zimara', Menberework Chanyalew ${ }^{2}$, Abraham Aseffa ${ }^{2}$, Ger van Zandbergen ${ }^{3}$, Bernd Lepenies ${ }^{4}$, Maximilian Schmid ${ }^{5}$, Richard Weiss ${ }^{6}$, Anne Rascle ${ }^{1 \dagger}$, Anja Kathrin Wege ${ }^{7}$, Jonathan Jantsch ${ }^{8}$, Valentin Schatz ${ }^{8}$, Gordon D. Brown ${ }^{9}$ and Uwe Ritter ${ }^{1 *}$

\begin{abstract}
Regensburg Center for Interventional Immunology (RCI), Institute of Immunology, University Medical Center Regensburg, University of Regensburg, Regensburg, Germany, ${ }^{2}$ Armauer Hansen Research Institute, Leishmaniasis Research Laboratory, Addis Ababa, Ethiopia, ${ }^{3}$ Federal Institute for Vaccines and Biomedicines, Division of Immunology, Paul Ehrlich Institute, Langen, Germany, ${ }^{4}$ University of Veterinary Medicine Hannover, Immunology Unit, Research Center for Emerging Infections and Zoonoses (RIZ), Hannover, Germany, ${ }^{5}$ Department of Internal Medicine III, Hematology and Oncology, University Hospital Regensburg, Regensburg, Germany, ${ }^{6}$ Department of Molecular Biology, Division of Allergy and Immunology, University of Salzburg, Salzburg, Austria, ${ }^{7}$ Department of Gynecology and Obstetrics, University Medical Center Regensburg, Regensburg, Germany, ${ }^{8}$ Institute of Clinical Microbiology and Hygiene, University Hospital of Regensburg, University of Regensburg, Regensburg, Germany, ${ }^{9}$ MRC Centre for Medical Mycology, University of Aberdeen, Aberdeen, United Kingdom
\end{abstract}

Resistant mouse strains mount a protective $T$ cell-mediated immune response upon infection with Leishmania (L.) parasites. Healing correlates with a T helper (Th) cell-type 1 response characterized by a pronounced IFN- $\gamma$ production, while susceptibility is associated with an IL-4-dependent Th2-type response. It has been shown that dermal dendritic cells are crucial for inducing protective Th1-mediated immunity. Additionally, there is growing evidence that $\mathrm{C}$-type lectin receptor (CLR)-mediated signaling is involved in directing adaptive immunity against pathogens. However, little is known about the function of the CLR Dectin-1 in modulating Th1- or Th2-type immune responses by DC subsets in leishmaniasis. We characterized the expression of Dectin-1 on CD11C ${ }^{+}$ DCs in peripheral blood, at the site of infection, and skin-draining lymph nodes of $L$. major-infected C57BL/6 and BALB/c mice and in peripheral blood of patients suffering from cutaneous leishmaniasis (CL). Both mouse strains responded with an expansion of Dectin-1+ DCs within the analyzed tissues. In accordance with the experimental model, Dectin-1+ DCs expanded as well in the peripheral blood of CL patients. To study the role of Dectin-1+ DCs in adaptive immunity against $L$. major, we analyzed the $T$ cell stimulating potential of bone marrow-derived dendritic cells (BMDCs) in the presence of the Dectin-1 agonist Curdlan. These experiments revealed that Curdlan induces the maturation of BMDCs and the expansion of Leishmania-specific CD4 ${ }^{+} T$ cells. Based on these findings, we evaluated the impact of Curdlan/Dectin-1 interactions in experimental leishmaniasis and were able to demonstrate that the presence of Curdlan at the site of infection modulates the course of disease in BALB/c mice: wild-type BALB/c mice 
treated intradermally with Curdlan developed a protective immune response against L. major whereas Dectin-1-1- BALB/c mice still developed the fatal course of disease after Curdlan treatment. Furthermore, the vaccination of BALB/c mice with a combination of soluble L. major antigens and Curdlan was able to provide a partial protection from severe leishmaniasis. These findings indicate that the ligation of Dectin-1 on DCs acts as an important checkpoint in adaptive immunity against $L$. major and should therefore be considered in future whole-organism vaccination strategies.

\section{Keywords: Curdlan, $\beta$-glucan, Dectin-1, cutaneous leishmaniasis, adaptive immunity, dendritic cells, T helper 1 and} T helper 2 cells

\section{INTRODUCTION}

Cutaneous leishmaniasis (CL) is a vector-borne parasitic infectious disease encountered in tropical and subtropical regions of the world (1). The causative agents are flagellated protozoans of the genus Leishmania (L.), which are inoculated into the skin during the blood meal of female sandflies. Different clinical manifestations in humans, ranging from a self-limiting cutaneous infection to disseminating visceral leishmaniasis (VL), are described with respect to the transmitting vectors and Leishmania species (2).

Comparable to the course of disease in humans, L. major parasites can develop cutaneous manifestations in C57BL/6 and $\mathrm{BALB} / \mathrm{c}$ mouse models (3). The infection of inbred mice with stationary phase promastigote Leishmania parasites allowed the examination of basic mechanisms, resulting in innate and adaptive T cell-mediated immunity (3).

It is known that L. major parasites require phagocytic cells for replication and spreading within the host (4). In this regard, neutrophils and macrophages play a pivotal role as host cells for the initial survival and spreading of parasites. However, macrophages produce leishmanicidal molecules after appropriate activation by certain T helper (Th) 1 cytokines such as IFN- $\gamma(3$, 5) and become effector cells during the host response against L. major. Thus, healing of CL in C57BL/6 mice is associated with a pronounced expansion of IFN- $\gamma$-secreting Th1 cells (6), whereas susceptibility of BALB/c mice is associated with a diminished IFN- $\gamma$, but increased IL-4-production in highdose infection models $(5,7,8)$. Therefore, $\mathrm{CD}^{+} \mathrm{T}$ cells are crucial key players in modulating antigen-specific immunity in leishmaniasis (3).

It is mostly accepted that Th1- and Th2-effector cells derive from a common $\mathrm{CD}^{+} \mathrm{T}$ cell precursor (9). Several stimuli have been reported to influence the pathway of maturation of these $\mathrm{CD}^{+} \mathrm{T}$ cell progenitors (10). Using $\mathrm{CD} 4^{+} \mathrm{T}$ cells, transgenic for a unique TCR alpha/beta receptor, it was proven that distinct cytokines such as IL-12 and IL-4 are crucial for the polarization of Th1 and Th2 cells $(5,10)$. Th1 cell differentiation takes place after Leishmania-specific $\mathrm{T}$ cells have been primed sufficiently by antigen-presenting cells in skindraining lymph nodes (SDLNs) (11). Based on the current model it must be assumed that Langerin ${ }^{-}$dermal dendritic cells (dDCs) are pivotal for the induction of the protective Th1-mediated immune response against L. major in C57BL/6 mice (12-14). Of note, Langerin ${ }^{+}$epidermal Langerhans cells are dispensable for the generation of protective immunity in experimental leishmaniasis (13-16).

T cell-mediated immunity against $L$. major parasites is a multistep process whereby mature DC subsets are pivotal to start the adaptive immune response within $\operatorname{SDLNs}(12,14)$. Maturation of DCs is accompanied by high expression of chemokine receptor (CCR) 7, paving the way to the SDLN and costimulatory molecules crucial for DC/T-cell communication (17). Certain cytokines such as TNF- $\alpha$ and IL- 6 are known to support this process $(17,18)$. Additionally, pattern recognition receptors (PRRs) binding pathogen components are also potent activators of DC maturation (19). Especially toll-like receptors that represent the most popular PRRs (20), recognize pathogen-associated molecular patterns derived from various pathogens, including viruses, bacteria, fungi, parasites, and protozoa, and are crucial for innate immune mechanisms (21).

The C-type lectin receptors (CLRs) also belong to PRRs and recognize predominantly carbohydrates and non-carbohydrates through mechanisms that are still not fully understood (22). The CLR Dectin- 1 recognizes $\beta$-glucans (22-25) that naturally occur in the cell wall of fungi (23). In addition to pathogen-derived factors, endogenous $\mathrm{N}$-glycans present on the surface of tumor cells also represent potential Dectin-1 ligands and trigger tumor killing by NK cells (26).

Mouse Dectin-1 is expressed by various immunologically relevant cells belonging to the adaptive and innate immune system. Preferentially, monocytes, macrophages, neutrophils, and a subset of T cells were described to be positive for Dectin-1 (27). There is growing evidence that engagement of Dectin-1 on DC subsets is crucial for T-cell polarization in experimental mouse models $(28,29)$. In humans, Dectin-1 is widely expressed by all monocyte populations as well as by macrophages, DC, neutrophils, eosinophils, and B cells $(27,30)$. In line with these findings, it was shown that the function of human Dectin- 1 is equivalent to that of mouse Dectin-1 (30). Thus, CLRs in general and Dectin-1 in particular might be considered as important checkpoints for adaptive immune responses.

It could be demonstrated that Dectin- $1^{-1-}$ macrophages from C57BL/6 mice show a slightly reduced capacity for phagocytosis of L. infantum parasites in vitro (31). Thus, Dectin-1 might be involved in the formation of parasitophorous vacuoles (32). In line with these findings, it is important to mention that infected macrophages from C57BL/6 show an enhanced expression of Dectin-1 after infection with L. amazonensis in vitro (33). 
Consequently, the pronounced Dectin-1 expression by infected myeloid cells might potentiate the uptake of parasites and favors the spreading of the obligatory intracellular parasites during the first stage of innate immunity. An interaction of Dectin-1 with parasite-derived carbohydrates was not identified so far. Nevertheless, $\beta$-glucan can activate infected macrophages from $\mathrm{BALB} / \mathrm{c}$ mice to control the replication of $L$. donovani parasites in vitro $(34,35)$. Additionally, it was shown that NK cells can also be activated by Aureobasidium-derived soluble branched $(1,3-1,6)-\beta$-glucan that results in enhanced cellular immunity against $L$. amazonensis parasites in $\mathrm{BALB} / \mathrm{c}$ mice (36). The scientific evidence, that $\beta$-glucan can modulate innate immune mechanisms against L. major parasites at the site of infection, is still pending.

Dectin-1 signaling is also discussed to be crucial in directing adaptive $\mathrm{T}$ cell-mediated immune responses. Thus far, it is known that Dectin-1 ligation by fungal components triggers Th1- and Th17-mediated immune responses against fungi (37-41). Accordingly, Dectin-1 deficiency results in impaired $\mathrm{T}$ cell-mediated immunity and loss of control of fungal infection (42). Long before Dectin-1 was described as a receptor for $\beta$-glucans, these glucose polysaccharides were used as adjuvants for immunization and systemic therapies of $\mathrm{VL}$ in $\mathrm{BALB} / \mathrm{c}$ and C57BL/6 mice (43-47). In line with this, Ghosh et al. were able to efficiently treat BALB/c mice infected with $L$. donovani by multiple intraperitoneal (i.p.) applications of the linear $\beta$-glucan Curdlan, which induced Th17-mediated adaptive immunity and macrophage activation (34). Most of the studies investigating the effect of $\beta$-glucans were carried out using VL-causing $L$. donovani parasites. However, one study is published demonstrating that multiple systemic applications (i.p. and i.v.) of $\beta$-glucan after infection of BALB/c mice with $L$. major parasites blocked lesion development or parasite spreading in normally susceptible $\mathrm{BALB} / \mathrm{c}$ mice (48). Whether Dectin-1 is responsible for the observed immunological phenomenon has not been shown until now. Furthermore, quantification and characterization of Dectin- $1^{+}$DCs in experimental leishmaniasis and in patients suffering from CL are missing.

In this study, we investigated the potential impact of $\beta$-glucan and of Dectin-1 on DC physiology and subsequent modulation of T-cell immunity. Here, we were able to demonstrate an expansion of Dectin-1+ DCs in experimental leishmaniasis as well as in patients suffering from CL. Additional studies revealed that intradermal application of $L$. major parasites in combination with Curdlan changes the course of leishmaniasis: BALB/c mice treated with Curdlan developed a protective immune response against L. major, whereas Dectin-1 $1^{-/}$BALB/c mice still suffered from a fatal course of disease after Curdlan treatment. Based on these data, it appears that Dectin-1/Curdlan interactions per se are sufficient to modulate Th-cell differentiation. Further in vitro studies were performed to explore the cellular mechanisms. One important finding was the change in the phenotype and functionality of infected DCs triggered by Curdlan. They increase the expression of Dectin-1 and costimulatory molecules and become potent antigen-presenting cells, capable of accelerating the expansion of L. major-specific T cells.
The results presented in this article support the view that Dectin- $1^{+}$DCs represent promising targets for modulating adaptive $\mathrm{T}$ cell-mediated immunity and should therefore be considered in future whole-organism vaccination strategies.

\section{MATERIALS AND METHODS}

\section{Human Samples}

7-10 mL of peripheral blood samples were collected from patients suffering from CL and Ethiopian healthy controls (EHCs) living in Oromo and Amhara regions of Ethiopia. The sample collection was permitted based on the local ethical committee (allowance number PO25/08, Addis Ababa, Ethiopia) and the national health research ethics review committee (approval number 310/227/07, Addis Ababa). Written informed consent was obtained from the participants of this study. CL was confirmed by positive parasite cultures and PCR analysis as described elsewhere (49). CL patients were excluded from the study if they show one of the following criteria: younger than 18 and older than 55 years, chronic lesions (more then 6 months), positive for HIV, clinical evidence for coinfections, and drug intake.

\section{Mice}

Female wild-type BALB/c and C57BL/6 mice (Janvier Labs, Le Genest St. Isle, France) were kept at the animal facility of the University of Regensburg under pathogen-free conditions. Dectin- $1^{-/-}$mice on BALB/c background [kindly provided by G.D. Brown, University of Aberdeen (50)] were bred and maintained under conventional animal housing conditions. All experiments and animal housing were performed according to the guidelines for the care and use of experimental animals. The animal work was approved by the local veterinary authorities of the district government based on the European guidelines and national regulations of the German Animal Protection Act (approval no. AZ 54-2532.105/11). Female animals between 6 and 12 weeks of age were used for experiments.

\section{Parasites and Infection of Mice}

Virulent L. major parasites (MHOM/IL/81/FE/BNI) were propagated in vitro in blood agar cultures as described previously (51). Stationary phase promastigotes from the third to seventh in vitro passage were harvested, washed four times, and resuspended in PBS. Mice were infected via intradermal injection of $3 \times 10^{6}$ stationary phase promastigotes in $30 \mu \mathrm{L}$ into the hind footpads. The increase in lesion size was monitored weekly by measuring the footpad thickness with a metric caliper (Kroeplin Schnelltaster, Schlüchtern, Germany). The increase in footpad thickness (\%) was determined as described elsewhere (52).

\section{Curdlan Application}

Curdlan (WAKO Chemicals $\mathrm{GmbH}$, Neuss, Germany) was dissolved in sterile PBS to a concentration of $50 \mu \mathrm{g} / \mu \mathrm{L} .3 \times 10^{6}$ stationary phase promastigotes were resuspended in $30 \mu \mathrm{L}$ of Curdlan solution and injected intradermally into the hind footpads. Alternatively, soluble L. major antigens [SLA; (15)] 
corresponding to $3 \times 10^{6}$ stationary phase promastigotes were used. The course of disease was monitored as described earlier.

\section{Quantification of L. major-Specific IgG Subtypes}

Serum from naïve mice and from mice infected with L. major parasites was prepared at the corresponding time point and thereafter stored at $-20^{\circ} \mathrm{C}$ until use. Detection of L. major-specific $\mathrm{IgG}_{1}$ (Invitrogen, Darmstadt, Germany), IgG $\mathrm{Ig}_{2 \mathrm{a}}$ (BD Pharmingen, Heidelberg), and $\operatorname{IgG}_{2 c}$ (Jackson ImmunoResearch, Hamburg Germany) isotypes were performed as described earlier (53). The results were standardized by calculation of relative ELISA units (REU). REU were determined by the formula: $\mathrm{OD}_{450}$ serum (infected mice)/OD 450 serum (naïve mice).

\section{Delayed-Type Hypersensitivity (DTH) Reaction}

Three weeks after L. major infection, SLA (corresponding to $3 \times 10^{6}$ parasites) was injected in a volume of $20 \mu \mathrm{L}$ in the foreleg. As a control, $20 \mu \mathrm{L}$ of PBS was injected in the contra lateral foreleg. The increase in swelling was measured with a metric caliper (Kroeplin Schnelltaster) and referred to the control foreleg. The swelling was measured with a metric caliper (Kroeplin Schnelltaster) after 24, 48, and $72 \mathrm{~h}$.

\section{Generation of Bone Marrow-Derived Dendritic Cells (BMDCs)}

Bone marrow-derived dendritic cells were generated as previously described (54). Bone marrow cells from C57BL/6 or BALB/c mice were seeded in $10 \mathrm{~cm}$ BD Tissue culture dishes at a density of $2 \times 10^{6}$ per dish in $10 \mathrm{~mL}$ of RPMI medium supplemented with $10 \%$ fetal calf serum (FCS; PAN Biotech $\mathrm{GmbH}$ ), penicillin-streptomycin, $50 \mu \mathrm{M} \beta-\mathrm{ME}$, and 10\% GM-CSF containing supernatant harvested from Ag8653 myeloma cells transfected with the gene encoding murine GM-CSF (kindly provided by B. Stockinger, NMRI, Mill Hill, London, UK). BMDCs were harvested on day 10 for $\mathrm{T}$ cell proliferation experiments.

\section{Generation of Bone Marrow-Derived Macrophages (BMDMs)}

Mouse BMDMs were generated from female BALB/c mice and cultured for 7 days in hydrophobic Teflon bags (FT FEP 100C Dupont, American Durafilm, Holliston, MA) as described earlier $(55,56)$. For killing experiments, BMDMs were pulse-infected with $L$. major promastigotes at a 1:30 ratio for $4 \mathrm{~h}$ as described earlier (56). After infection, extracellular promastigotes were removed by washing with $\mathrm{PBS}$ and cultured in the absence or presence of Curdlan $(50,100$, and $250 \mu \mathrm{g} / \mathrm{mL}$ ) or LPS/IFN- $\gamma$ (10 and $20 \mathrm{ng} / \mathrm{mL}$, respectively). After $72 \mathrm{~h}$, BMDMs were fixed, stained, and analyzed microscopically using Diff-Quick staining (Medion Diagnostics, Düdingen, Switzerland) for the determination of the percentage of infected cells and the number of parasites per infected cell. LPS (Escherichia coli O111:B4) was purchased from Sigma-Aldrich (Taufkirchen, Germany). Recombinant murine IFN- $\gamma$ was purchased from eBioscience (Frankfurt, Germany).

\section{Nitrite Accumulation}

Nitrite accumulation in the supernatants was determined as an indicator for NO activity after stimulation of BMDMs using the Griess reaction as described earlier (56).

\section{Labeling of Leishmania Parasites with CFSE}

Stationary phase promastigotes from the third to seventh in vitro passage were harvested, washed four times, and resuspended in PBS. After lysis of the remaining erythrocytes, parasites were labeled by incubation in $1 \mu \mathrm{M}$ CFSE staining solution as described earlier (57).

\section{Leishmania-Specific T Cell Proliferation Assay}

C57BL/6 and BALB/c mice were infected with L. major parasites as described earlier. Ten days post infection, SDLNs were removed, and T cells were enriched untouched via MACS separation columns (Miltenyi Biotec, Bergisch Gladbach) according to the manufacturer's guidelines. Single-cell suspensions were labeled with PE-conjugated CD11b, CD11c, and B220 antibodies (Abs) and subsequently detected with anti-PE Beads (Miltenyi Biotec) in order to deplete myeloid cells and B cells. The purified T cells were labeled with CFSE as described earlier (15). $2 \times 10^{5}$ CFSE-labeled $\mathrm{T}$ cells were seeded in 96-well round-bottom plates (Nunc) to $2 \times 10^{4}$ BMDCs that have been primed for $24 \mathrm{~h}$ with SLA (as an equivalent of 5 parasites: 1 BMDC) or L. major parasites (10 parasites: $1 \mathrm{BMDC}$ ) in the presence or absence of Curdlan $(50 \mu \mathrm{g} / 200 \mu \mathrm{L}) .72 \mathrm{~h}$ after coculture, the cells were analyzed by flow cytometry. The proliferation index of samples was calculated according to the formula: (number of proliferating cells after stimulation)/(number of proliferating cells in the absence of stimulation). The proliferation index of stimulated samples was then normalized to that of unstimulated BMDC/Tcell cultures. Supernatants were collected and stored at $-80^{\circ} \mathrm{C}$ for cytokine analysis.

\section{CLR-Fc Fusion Protein Staining of Parasites}

The CLR-Fc fusion proteins (Dectin-1, CLEC-9a, and MGL-1) were prepared as described previously (58). After blocking (PBS/10\% FCS/10\% mouse serum), L. major parasites were washed three times in PBS. To analyze interactions with CLRs, parasites were incubated with $20 \mu \mathrm{g} / \mathrm{mL}$ of CLR-Fc fusion proteins diluted in lectin binding buffer (50 mM HEPES, $5 \mathrm{mM} \mathrm{MgCl}_{2}$, and $5 \mathrm{mM} \mathrm{CaCl}_{2}$, in $\left.\mathrm{dH}_{2} \mathrm{O}, \mathrm{pH} 7,4\right)$ at $4^{\circ} \mathrm{C}$ for $1 \mathrm{~h}$. After three washing steps with PBS, CLR-Fc binding to L. major was detected with a FITC-conjugated goat anti-hFc Ab (Dianova, Hamburg, Germany). Parasite DNA was detected with 6-diamidino-2-phenylindole obtained from Sigma Aldrich, as described earlier (59). After mounting with PermaFluor (Thermo Scientific, Dreieich, Germany), the sections were analyzed using Axio Imager.M1 (Zeiss, Jena, Germany) equipped with high-sensitivity gray scale digital camera (AxioCam MRm, Zeiss). Separate images were collected for each section, analyzed, and merged afterward (acquisition software: Zeiss AxioVision 4.6.3). Final image processing for 
illustrations was performed using Adobe Photoshop Elements (Adobe Systems GmbH, Munich, Germany).

\section{Flow Cytometry Analysis of Mouse Samples}

Single-cell suspensions of tissues were generated as described elsewhere (60). The following Abs and reagents were used for phenotyping of single-cells: PE-labeled anti-mouse CD11c Ab (clone N418; eBioscience, Frankfurt, Germany), APC-labeled anti-mouse CD11b (clone M1/70, eBioscience, Germany), PE-labeled anti-mouse F4/80 (clone 521204, R\&D), biotinylated anti-mouse Dectin-1 Ab (clone 2A11; Bio-Rad AbD Serotec GmbH, Puchheim, Germany), AlexaFluor647-labeled antimouse CD86 Ab (clone GL-1; BioLegend, San Diego, CA, USA), and FITC-labeled anti-BrdU Ab (clone B44; BD Pharmingen, Heidelberg, Germany). Depending on the experimental setup, the detection of biotinylated anti-mouse Dectin-1 was performed using streptavidin-conjugated to V500 (BD, Pharmingen, \#561419), eFluor450 (eBioscience, \#48-4317-82), Pacific Orange (Thermo Fisher, Munich, Germany), or PerCP (BD, Pharmingen, \#554064). Ab specificity was verified using appropriate isotype controls and Dectin-1 ${ }^{-/-}$mice (Figure S1 in Supplementary Material). Multicolor flow cytometry was performed as described previously (13). Mice were fed with BrdU-containing drinking water $(0.8 \mathrm{mg} / \mathrm{mL}$, Sigma, Deisenhofen, Germany) starting 3 days before the termination of the experiment. BrdU labeling was performed according to the manufacturer's instructions (BD Pharmingen, Heidelberg, Germany). After labeling of surface epitopes, the cells were fixed and permeabilized with Cytofix/ Cytoperm buffer (BD Pharmingen, Heidelberg, Germany) for $30 \mathrm{~min}$ on ice and afterward incubated for $10 \mathrm{~min}$ on ice with $0.01 \%$ Triton X-100 (SERVA, Heidelberg, Germany) in PBS/0.1\% BSA (PAN, Aidenbach, Germany). For the detection of incorporated BrdU, the cells were treated with $30 \mu \mathrm{g}$ DNAse (Sigma, Munich, Germany) for $1 \mathrm{~h}$ at $37^{\circ} \mathrm{C}$. Labeling of cells with anti-BrdU Ab was performed for $20 \mathrm{~min}$ at room temperature. Cells were collected using BD ${ }^{\mathrm{TM}}$ LSRII Flow Cytometer (BD Biosciences, Heidelberg, Germany) and analyzed with FlowJo software (Tree Star Inc., Ashland, OR, USA). The determination of the total cell numbers in tissues was performed as described earlier (61).

\section{Flow Cytometry Analysis of Human Samples}

Surface antigens were detected on fresh cells using a modified version of the method described by Aldebert et al. (62). 7-10 mL of blood from patients and EHCs were taken with BD Vacutainer (BD Biosciences, UK) containing $170 \mathrm{IU}$ of lithium heparin. $200 \mu \mathrm{L}$ of whole blood cells was incubated for 20 min with FcR blocking reagent (Miltenyi Biotec $\mathrm{GmbH}$, Germany). The staining was performed for $30 \mathrm{~min}$ at $4^{\circ} \mathrm{C}$. The following Abs were used: FITC-labeled anti-lineage (Lin) panel (CD3, CD14, CD16, CD19, CD20, and CD56) (BD), PerCP-labeled anti-HLA-DR (R\&D, clone L203), PE-labeled anti-CD123 (R\&D, clone 32703), PE-Cy5.5-labeled anti-CD11c (BD, clone B-Ly6), and APClabeled anti-Dectin-1 (R\&D, clone 259931). Erythrocytes were lysed with BD FACS ${ }^{\mathrm{TM}}$ Lysing Solution (BD Biosciences), and the remaining white blood cells were washed and resuspended in FACS buffer (PBS buffer, pH 7.2 1\% BSA fraction V, Roth, 8076.2), $0.01 \% \mathrm{NaN}_{3}$ (Sigma: S2002-25G), and 1\% human serum. A total of 200,000 events were acquired and the positive population gated using the isotype controls for the different fluorochromes. Data were acquired with a FACS Canto flow cytometer (BD Bioscience). Data analysis was performed with FlowJo 8.8.6.

\section{Gene Expression Analysis by Quantitative RT-PCR}

$\mathrm{CD}^{+}{ }^{+} \mathrm{T}$ cells were sorted with the $\mathrm{CD} 4{ }^{+}$Cell isolation $\mathrm{Kit}^{\circledR}$ (Miltenyi Biotec, Bergisch Gladbach, Germany) according to the manufacturer's specification. Following cell sorting, the $\mathrm{CD}^{+}$cells were lysed in $350 \mu \mathrm{L}$ Buffer RA1 (Macherey-Nagel, Düren, Germany) supplemented with $3.5 \mu \mathrm{L} \beta$-ME. Total RNAs were isolated using the NucleoSpin ${ }^{\circledR}$ RNA kit (Macherey-Nagel), following the manufacturer's instructions. RNAs were quantified by spectrophotometry and $170 \mathrm{ng}$ of RNAs were used for cDNA synthesis using the iScript cDNA Synthesis kit (Bio-Rad Laboratories, München, Germany), as recommended by the manufacturer. Quantitative PCR was performed on a RotorGene Q (Qiagen, Hilden, Germany) using a two-step PCR program $\left(95^{\circ} \mathrm{C}\right.$ $15 \mathrm{~s}, 60^{\circ} \mathrm{C} 60 \mathrm{~s} ; 40$ cycles). $20 \mu \mathrm{L}$ quantitative PCR reactions were performed using $0.3-0.6 \mu \mathrm{L}$ of cDNA template (corresponding to 2.5-5 ng RNA equivalent) and a self-made master-mix containing SYBR Green I and HotStarTaq DNA Polymerase (Qiagen). Data were normalized to GAPDH mRNAs and expressed as relative mRNA levels, as previously reported $(63,64)$. Forward (fwd) and reverse (rev) mouse-specific quantitative PCR primers were as follows: GAPDH, 5'-AGCTTGTCATCAACGGGAAG-3' (fwd) and 5' ${ }^{\prime}$ TTTGATGTTAGTGGGGTCTCG-3' (rev); GATA, 5' -CC AAGGCACGATCCAGCACAGA-3' (fwd) and 5'-GGCCGACA GCCTTCGCTTGG-3' (rev); IFNG, 5' -AGGTCAACAACCCAC AGGTCC-3' (fwd) and 5'-GATTCCGGCAACAGCTGGT-3' (rev);IL-4, 5' -ACAGGAGAAGGGACGCCAT-3' (fwd)and $5^{\prime}$-GA AGCCCTACAGACGAGCTCA-3' (rev); IL-17A, 5' -AACTCCCT TGGCGCAAAAG-3' (fwd) and 5'-GAGAGTCCAGGGTGACG TGG-3' (rev); STAT4, 5' -CCTGGGTGGACCAATCTGAA-3' (fwd) and 5'-CTCGCAGGATGTCAGCGAA-3' (rev); STAT6, $5^{\prime}$-CCCCAACAAACTTCTCATCCA-3' (fwd) and 5' -TTTGGC GTTGTTGTCTTGGTT-3' (rev); andT-BET, 5' -ACCAACAACA AGGGGGCTCT-3' (fwd) and $5^{\prime}$-CTCTGGCTCTCCATCATTC ACC-3' (rev).

\section{Quantification of L. major Parasites}

To measure the parasite burden, genomic DNA was isolated using DNA purification solutions from QIAGEN (QIAGEN, Hilden, Germany). In brief, the cells were digested in cell lysis solution directly in the well. Protein was removed by adding protein precipitation buffer, and DNA was precipitated according to the manufacturer's instructions with 100\% 2-propanol (Sigma Aldrich, Taufkirchen, Germany). The concentration of mouse $\beta$-actin-DNA was quantified by PCR (65). The Leishmania DNA concentrations in the same samples were determined using fluorescence resonance energy transfer real-time PCR with Leishmanial $18 \mathrm{~S}$ ribosomal DNA sequences (66). The resulting 
Leishmania DNA copy number was then divided by the copy number of $\beta$-actin-DNA to obtain the relative parasite units (RPU).

\section{Quantification of Cytokines}

Supernatants of cell cultures were analyzed with a FlowCytomix ${ }^{\mathrm{TM}}$ kit (IL-13, IL-1 $\alpha$, IL-22, IL-2, IL-21, IL-6, IL-10, IL-27, IFN- $\gamma$, TNF- $\alpha$, IL-4, and IL-17) according to the manufacturer's (eBioscience, Thermo Fisher Scientific, Waltham, USA) specifications. Acquisition of probes was performed with a FACS Canto II (BD Bioscience).

\section{Statistical Analysis}

Statistical significance between groups were calculated by different tests: two-way ANOVA for comparing the footpad swelling of analyzed groups, non-parametric Mann-Whitney tests if no normal distribution (no Gaussian distribution) was determined, and two-tailed Student's $t$-test if normal distribution (Gaussian distribution) was determined. The calculation was performed using PRISM software (GraphPad, La Jolla, CA, USA). The corresponding $p$ values are highlighted by stars only if $p<0.050$.

\section{RESULTS}

\section{Local Infection with Leishmania Parasites Results in Systemic Expansion of Dectin-1+ DCs in Patients Suffering from CL}

DCs are known to be important checkpoints for the generation of $\mathrm{T}$ cell-mediated protective immunity in experimental leishmaniasis (67). Based on the potential role of Dectin- $1^{+}$DCs in adaptive immunity, we addressed the question whether a cutaneous infection with Leishmania parasites results in an expansion of Dectin- $1^{+}$DCs.

In humans, it is difficult to analyze the dynamics of DC populations in tissues or secondary lymphoid organs. Therefore, we focused on the analyses of blood samples. DCs in the peripheral blood lack certain Lin-specific markers (68). Thus, Lin ${ }^{-}$leukocytes were used for further characterization of human DCs (Figures 1A,B). The $\mathrm{Lin}^{-}$population consists of $\mathrm{HLA}^{-\mathrm{DR}^{-}}$and

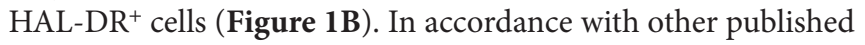
data, the $\mathrm{Lin}^{-}$CD11 $\mathrm{c}^{+}$cells are positive for HLA-DR and could be found within the $\mathrm{Lin}^{-} / \mathrm{HLA}-\mathrm{DR}^{+}$population $(68,69)$ (data not shown).

On the basis of the markers CD11c and CD123 $(68,70)$ myeloid DCs (mDC; CD11 $\left.\mathrm{c}^{+} / \mathrm{CD} 123^{- \text {int }}\right)$ were dissected from plasmacytoid DC (pDC; CD11c $/$ CD $123^{\text {bright }}$ ) subsets (Figure 1C). We could demonstrate that pDCs from EHCs and CL patients hardly express Dectin-1 (Figure 1D). The expression of Dectin-1 is predominantly restricted to $\mathrm{mDCs}$ (Figure 1D). Cutaneous infection with Leishmania parasites results in an increased frequency of Dectin- $1^{+}$-positive $\mathrm{mDCs}$ in the periphery compared to healthy controls (Figure 1E). Of note, the pDC subset does not show significant differences in Dectin-1 expression between EHCs and patients suffering from CL (Figure 1F). These data suggest that a local infection with Leishmania parasite results in
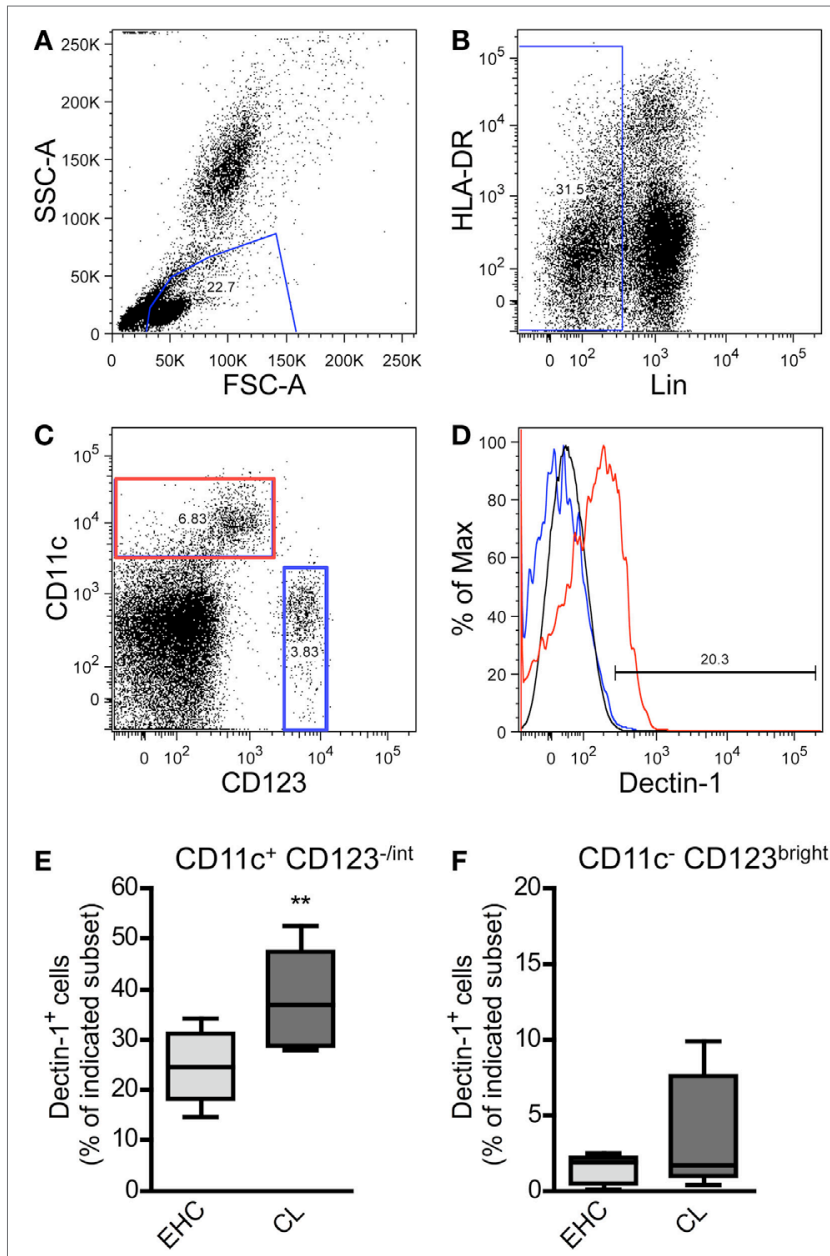

FIGURE 1 | Characterization of Dectin-1+ DC subsets in blood samples from patients suffering from cutaneous leishmaniasis (CL). Peripheral blood samples from patients suffering from $\mathrm{CL}$ and Ethiopian healthy controls (EHCs) were stained for CD11c, Dectin-1, HLA-DR, CD123, and a lineage cocktail (anti-CD3, anti-CD14, anti-CD16, anti-CD19, anti-CD20, and anti-CD56) abbreviated as Lin. The following gating strategy was used. (A) FSC and SSC plots were used to define the leukocyte population. (B) Lin- cells were selected for further analysis. (C) Lin- cells were differentiated into $\mathrm{CD} 11 \mathrm{C}^{+} / \mathrm{CD} 123^{- \text {-int }}$ and CD11 $\mathrm{C}^{-} / \mathrm{CD} 123^{\text {bright }}$ populations displayed as dot plot. (D) The histogram plot indicates the expression of Dectin-1 on CD11 $\mathrm{C}^{+}$/ CD123-int (highlighted in red) and CD11c-/CD123 ${ }^{\text {bright }}$ cells (highlighted in blue). The black line represents the isotype control. (E,F) The frequency of Dectin-1+ cells within the indicated subset is shown by box plot diagrams. Number of analyzed donors, $n=5$. Data were analyzed using Student's $t$-test $\left({ }^{\star *} p=0.004\right)$.

the expansion of Dectin- $1^{+} \mathrm{mDC}$ subsets in the peripheral blood of CL patients.

\section{Local Infection with Leishmania Parasites Results in Systemic Proliferation of Dectin-1+ DCs in BALB/C and C57BL/6 Mice}

CD11c is hardly expressed by pDCs in mouse models $(71,72)$. Thus, most of the CD11c $c^{+/ b r i g h t}$ DCs belong to the subset of 
conventional DCs including other mDC subsets $(73,74)$. In CL patients, Dectin- $1^{+}$mDCs expand after infection. To prove the concept that a local infection also results in a systemic expansion of Dectin- $1^{+}$mDCs, C57BL/6 and BALB/c mice were infected intradermally with $L$. major parasites. SDLNs, the site of infection, and the peripheral blood were analyzed for proliferating Dectin- $1^{+}$ CD11 $\mathrm{c}^{+/ \text {bright }}$ DCs. Mice were administered the thymidine analog BrdU, as described in Section "Materials and Methods," to analyze cell proliferation in vivo. 13 days after infection, when clinical symptoms such as footpad swelling occur and Leishmania-specific T cell-mediated immunity is initiated $(13,60)$, Dectin-1 was measured on $\mathrm{BrdU}^{+}$(proliferating) and $\mathrm{BrdU}^{-}$(resting) $\mathrm{CD}_{11 \mathrm{c}^{+}}$ DCs (Figures 2A,B). Detailed quantification of Dectin- $1^{+}$DCs within proliferating and resting $\mathrm{CD} 11 \mathrm{c}^{+} \mathrm{DCs}$ revealed that both subsets express Dectin-1. However, the frequency of Dectin- $1^{+}$ $\mathrm{CD} 11 \mathrm{c}^{+} \mathrm{DCs}$ is substantially higher within the proliferating subset compared to the resting $\mathrm{CD} 11 \mathrm{c}^{+} \mathrm{DCs}$ of $\mathrm{BALB} / \mathrm{c}$ and $\mathrm{C} 57 \mathrm{BL} / 6$ mice (Figures 2C,D). Further analysis of the site of infection and SDLNs of infected BALB/c and C57BL/6 mice confirmed this result (Figures S2A,B in Supplementary Material). These data generated from mice reflect the results obtained in CL patients, indicating that a local infection with Leishmania parasites results in a systemic expansion of Dectin-1+ DCs.

\section{The Presence of Curdlan at the Site of Infection Results in an Adaptive Immune Response in Normally Susceptible BALB/c Mice}

So far, only systemically (i.p. and/or i.v.) applied $\beta$-glucans have been used to treat $\mathrm{BALB} / \mathrm{c}$ or $\mathrm{C} 57 \mathrm{BL} / 6$ mice after infection (34, 43-48). No published data exist analyzing the effects of cutaneous application of $\beta$-glucan such as Curdlan in parallel to L. major infection. Given that Dectin- $1^{+}$DCs expand at the site of infection and within SDLNs (Figure 2; Figure S2 in Supplementary Material), it seems feasible that a local stimulation of Dectin- $1^{+}$DCs with Curdlan modulates the parasite-specific immune response. To test this hypothesis, $\mathrm{BALB} / \mathrm{c}$ and $\mathrm{C} 57 \mathrm{BL} / 6$ mice were infected with promastigote parasites suspended in PBS plus Curdlan. The course of infection was not substantially modulated in resistant C57BL/6 mice (Figure S3 in Supplementary Material). In contrast, normally susceptible BALB/c mice showed a resistant phenotype when the parasites were intradermally injected in combination with Curdlan (Figure 3A). BALB/c mice infected with $L$. major alone displayed the well-known severe course of disease (Figure 3A). An additional control experiment with Dectin $-1^{-/-} \mathrm{BALB} / \mathrm{c}$ was performed to confirm the specificity of the Curdlan/Dectin-1 interaction in vivo. Here, we were able to demonstrate that an application of Curdlan together with the parasites does not result in protective immunity against $L$. major parasites as shown in protected BALB/c wild-type mice (WT) (Figure 3A; Figure S4 in Supplementary Material). The experiments with non-healing $\mathrm{BALB} / \mathrm{c}$ WT and Dectin- $1^{-/-}$mice had to be terminated based on the severe ulcerated footpads.

C57BL/6 mice usually resolve a primary infection with L. major. Following resolution of the primary infection, they are

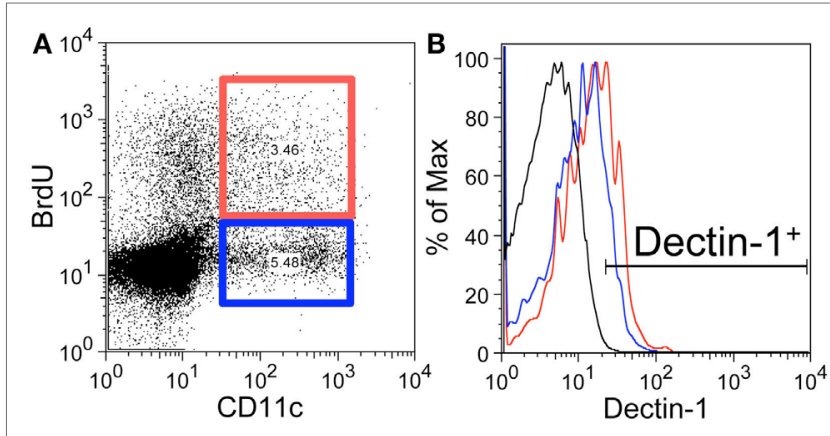

C

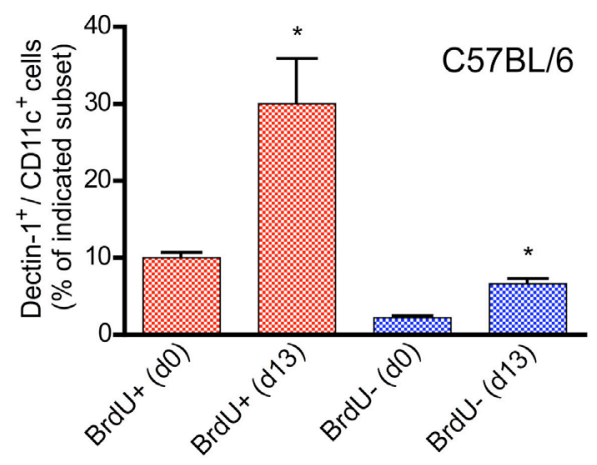

D

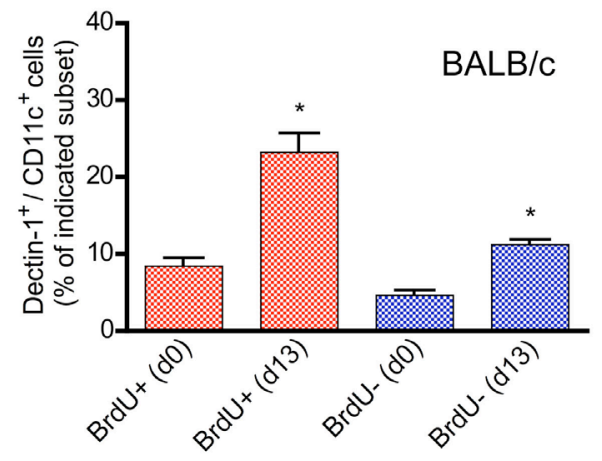

FIGURE 2 | Characterization of Dectin-1 expression on proliferating CD11 $\mathrm{C}^{+}$DCs in blood samples of infected C57BL/6 and BALB/c mice. Mice were infected intradermally with Leishmania major parasites into the hind footpad, and the peripheral blood was analyzed 13 days after infection. Naïve mice served as controls (day 0 ). BrdU+ was given 3 days before the analysis. Peripheral blood leukocytes were gated. (A) The dot plot diagram displays the $\mathrm{CD} 11 \mathrm{c}$ and $\mathrm{BrdU}$ intensities. $\mathrm{BrdU}+/ \mathrm{CD} 11 \mathrm{c}^{+}$cells are highlighted by a red and BrdU-/CD $11 \mathrm{c}^{+}$by a blue gate. (B) Dectin-1 expression of the $\mathrm{BrdU}$ subsets is shown as histogram displaying isotype control in black, $\mathrm{BrdU}+/ \mathrm{CD} 11 \mathrm{c}^{+}$cells in red, and $\mathrm{BrdU}-/ \mathrm{CD} 1 \mathrm{c}^{+}$cells in blue line. (C) The frequencies of Dectin- $1^{+} / \mathrm{CD} 11 \mathrm{C}^{+}$cells (blue bars, BrdU-/

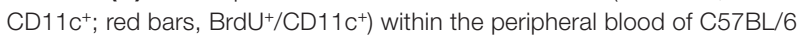
mice were analyzed. Pooled data from three different experiments are shown (mean $\pm \mathrm{SD}$ ). Data were analyzed using Student's $t$-test $\left.{ }^{* \star *} p=0.004,{ }^{* \star \star} p=0.0003\right)$. (D) The frequencies of Dectin $-1^{+} / \mathrm{CD} 11 \mathrm{c}^{+}$ cells (blue bars, BrdU-/CD11 $\mathrm{c}^{+}$; red bars, $\mathrm{BrdU}+/ \mathrm{CD} 11 \mathrm{C}^{+}$) within the peripheral blood of BALB/c mice are indicated (mean \pm SD). Pooled data from three different experiments were analyzed using the non-parametric Mann-Whitney test $\left({ }^{*} p<0.5\right)$.

immune to reinfection due to the generation of antigen-specific memory $\mathrm{T}$ cells $(75,76)$. To test whether Curdlan-protected $\mathrm{BALB} / \mathrm{c}$ mice (Figure 3A) show classical signs of adaptive 
immunity, reinfection experiments were performed. BALB/c mice that had received Curdlan intradermally in the absence of parasites were used to exclude the possibility of an unspecific expansion of $\mathrm{T}$ cells potentially mediating protection. Resistant $\mathrm{BALB} / \mathrm{c}$ mice, that had been infected with $L$. major parasites in the presence of Curdlan, were reinfected into the contra lateral footpad at day 131 after primary infection with a high-dose of parasites in the absence of Curdlan. At this time point, no clinical signs such as footpad swelling were detectable. BALB/c mice that have been treated intradermally only with Curdlan 131 days before the primary infection developed a severe course of disease, that is, comparable to infected $\mathrm{BALB} / \mathrm{c}$ mice that were not pretreated (Figure 3B). In contrast, protected BALB/c mice, that resolved the primary infection, were able to rapidly control the second round of a high-dose infection with Leishmania parasites in the absence of Curdlan (Figure 3B). These mice now show
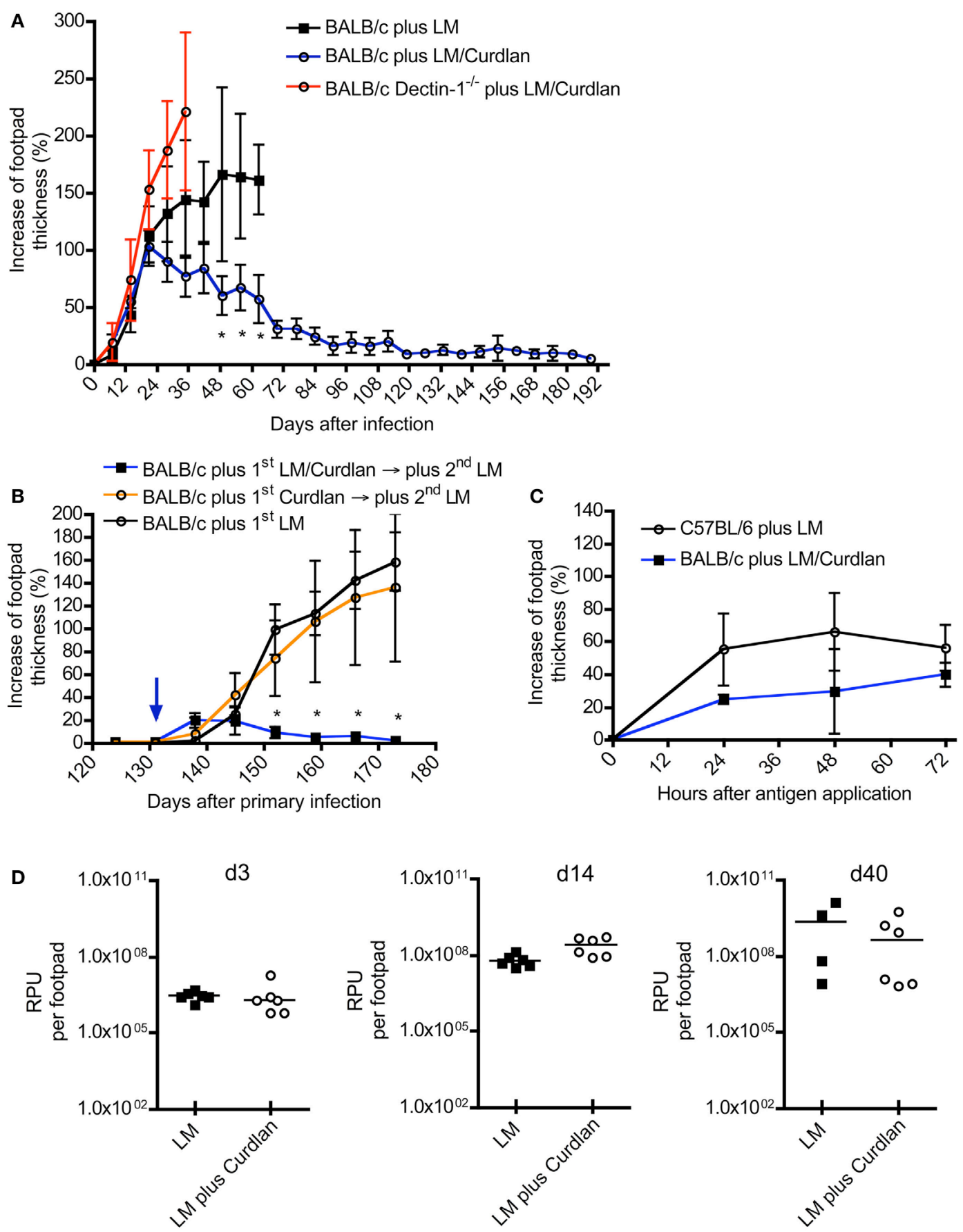

FIGURE 3 | Continued 
FIGURE 3 | The presence of Curdlan at the site of infection results in an adaptive immune response in normally susceptible BALB/c. (A) BALB/C control mice were infected intradermally with Leishmania (L.) major into the right footpad (black line, black squares; $3 \times 10^{6}$ parasites/30 $\mu \mathrm{L} ; n=19$ ), abbreviated as BALB/c plus LM. Another group of BALB/c mice was infected with $30 \mu \mathrm{L}$ of mixture of $3 \times 10^{6}$ parasites and Curdlan $(c=50 \mu \mathrm{g} / \mu \mathrm{L}$, blue line, black circles; $n=16)$, abbreviated as BALB/c plus LM/Curdlan. BALB/c mice deficient for Dectin-1 were also infected with $30 \mu \mathrm{L}$ of a mixture of $3 \times 10^{6}$ parasites and Curdlan $(c=50 \mu g / \mu L$, red line, black circles; $n=5$ ), abbreviated as BALB/c Dectin-1-/- plus LM/Curdlan. Based on severe necrosis of the infected footpads, the groups BALB/c plus LM and BALB/c Dectin-1-/- plus LM/Curdlan had to be terminated at days 60 and 36, respectively. The $y$-axis depicts the increase in footpad thickness (mean \pm SD). Data were analyzed using Student's $t$-test and highlighted if differences are significant ( ${ }^{*} p<0.05$; BALB/c plus LM compared to BALB/c plus LM/Curdlan). (B) Resistant $\mathrm{BALB} / \mathrm{c}$ mice that had been treated with Curdlan in the presence of $L$. major parasites were reinfected at day 131 (blue arrow) after primary infection (abbreviated as BALB/c plus 1st LM/Curdlan $\rightarrow$ 2nd LM, blue line, black squares; $n=3$ ). BALB/c mice that had been treated with Curdlan alone 131 days before (abbreviated as BALB/c plus 1st Curdlan $\rightarrow$ 2nd LM, orange line, black circles; $n=3$ ) were also infected. Naïve BALB/c mice were infected (BALB/c plus 1st LM, black line, black circle; $n=5$ ), too. The $y$-axis depicts the increase in footpad thickness (mean \pm SD). Data (BALB/c plus 1st LM compared to BALB/c plus 1 st LM/Curdlan $\rightarrow 2 n d$ LM) were analyzed using two-way ANOVA ( $\left.{ }^{*} p<0.05\right)$. (C) A delayed-type hypersensitivity (DTH) response is shown, comparing C57BL/6 mice infected with $3 \times 10^{6}$ parasites (plus LM, black line, black circles; $n=3$ ) with BALB/c mice infected with $3 \times 10^{6}$ parasites plus Curdlan (plus LM/Curdlan, blue line, black squares; $n=3$ ). The DTH response was induced 217 days after primary infection as described in Section "Materials and Methods." The $y$-axis depicts the increase in footpad thickness (mean $\pm \mathrm{SD}$ ), the $x$-axis hours after antigen application. (D) Relative parasite units (RPU) representing the relative amount of parasites per footpad at days 3, 14, and 40 after infection are displayed. Infected BALB/c mice (LM, black squares) were compared with BALB/c mice that had been infected with parasites plus Curdlan (LM plus Curdlan, black circles). The mean (horizontal line) is shown. Each circle or square represents one analyzed footpad. Data were analyzed using Student's $t$-test (d3 $p=0.779$, d14 $p=0.062$, and d40 $p=0.286$ ).

symptoms of an infection until the termination of the experiment 120 after the second exposition to Leishmania parasites in the absence of Curdlan.

Beside a reinfection, the DTH response is also an accepted indicator for the presence of an adaptive $\mathrm{T}$ cell-mediated immune response $(75,77)$. In contrast to resistant $\mathrm{C} 57 \mathrm{BL} / 6$ mice, $\mathrm{BALB} / \mathrm{c}$ mice hardly generate a measurable DTH reaction after a high-dose infection with L. major parasites (52). Using the high-dose model, we were able to demonstrate that Curdlan-protected BALB/c mice can indeed develop a DTH reaction that is comparable to that of resistant C57BL/6 mice (Figure 3C). Consequently, protected $\mathrm{BALB} / \mathrm{c}$ mice mount an adaptive $\mathrm{T}$ cell-mediated immunity against $L$. major parasites that is accompanied by a clear reduction of the parasite load at the site of infection during the effector phase of experimental leishmaniasis (Figure S5 in Supplementary Material).

It needs to be mentioned that $\mathrm{BALB} / \mathrm{c}$ mice can develop protective immunity against $L$. major if they have been infected with a low dose of parasites (8). Thus, we had to exclude that skin-homing macrophages eliminate the parasites after Curdlan contact shortly after infection. A milder course of disease would be the artificial consequence. In line with published data $(31,33)$, we were able to demonstrate that macrophages express Dectin-1 in the presence or absence of parasites (Figures S6A-D in Supplementary Material). However, Curdlan activation does not induce leishmanicidal mechanisms resulting in the elimination of L. major parasites (Figure S7 in Supplementary Material). In line with this finding, we were able to show that Curdlan-treated and control BALB/c mice show the same parasite burden at the site of infection during the early phase (days 3 and 14) of experimental leishmaniasis (Figure 3D). At day 40, after infection the beneficial effect of Curdlan treatment (the effect of Curdlan treatment on the parasite load at day 80 after infection, is shown in Figure S5 in Supplementary Material) is slightly indicated but not significant (Figure 3D).

In conclusion, we can demonstrate that the presence of Curdlan at the time of intradermal infection does not induce antigen-unspecific side effects but triggers the modulation of an adaptive T-cell response of BALB/c mice in a Dectin-1-dependent manner: they develop a resistant phenotype.

\section{Cutaneous Curdlan Application Dampens the Th2 Response of Infected BALB/c Mice}

The rapid clearance of $L$. major parasites after a high-dose reinfection and the positive DTH response of protected BALB/c mice (Figures 3B,C) supports the hypothesis that an adaptive Th1 response was generated. To assess that possibility, Leishmaniaspecific IgG subtypes, Th1- and Th2-indicating cytokines, and selected transcription factors were characterized.

Protective immunity to L. major infection does not depend on the production of specific Abs (78). However, L. major-specific IgG responses are an indication for the ability of the host organism to mount an antigen-specific immune reaction. In experimental leishmaniasis, $\mathrm{BALB} / \mathrm{c}$ mice mount a Th2 response and produce predominantly $\operatorname{IgG}_{1}$, whereas resistant $\mathrm{C} 57 \mathrm{BL} / 6$ mice develop a Th1 response and an increased production of $\operatorname{IgG}_{2 c} \mathrm{Abs}(3,79)$. An increase in parasite-specific $\operatorname{IgG}_{2 c}$ is therefore an indicator for an ongoing protective Th1 response. In mouse strains with the Igh1- $a$ allele, like BALB/c, the $\operatorname{IgG}_{2 c}$ gene is deleted (80). Thus, we determined Leishmania-specific $\operatorname{IgG}_{1}$ and $\operatorname{IgG}_{2 \mathrm{a}}$ subsets in sera of $\mathrm{BALB} / \mathrm{c}$ mice that had been infected in the presence or absence of Curdlan. First, we analyzed mice that had not been treated with Curdlan. C57BL/6 and BALB/c mice generated Leishmania-specific $\mathrm{IgG}_{1} 25$ days after infection (Figure 4A). In contrast, C57BL/6 mice produced a significantly higher amount of $\operatorname{IgG}_{2 \mathrm{a}}$ isotypes compared to susceptible BALB/c mice (Figure 4B). The infection in the presence of Curdlan led to an increase in Leishmania-specific $\operatorname{IgG}_{2 \mathrm{a}}$ in $\mathrm{BALB} / \mathrm{c}$ mice (Figure 4C) that also provoked a higher $\operatorname{IgG}_{2 \mathrm{a}} / \mathrm{IgG}_{1}$ ratio of Leishmania-specific Abs (Figure 4D). Based on these data, we conclude that Curdlan treatment might dampen the development of a disease-promoting Th2 response in BALB/c mice.

In our study, we used a high-dose infection model and could demonstrate that Curdlan application results in protective immunity in BALB/c mice (Figure 3). It is important to mention that $\mathrm{BALB} / \mathrm{c}$ mice do not necessarily develop a severe course of disease. In low-dose infection models, BALB/c mice develop a resistant phenotype, accompanied by the polarization toward a Th1-like phenotype (8). Thus, $\mathrm{CD}^{+} \mathrm{T}$ cells from $\mathrm{BALB} / \mathrm{c}$ mice can also differentiate into Th1 cells. 
A
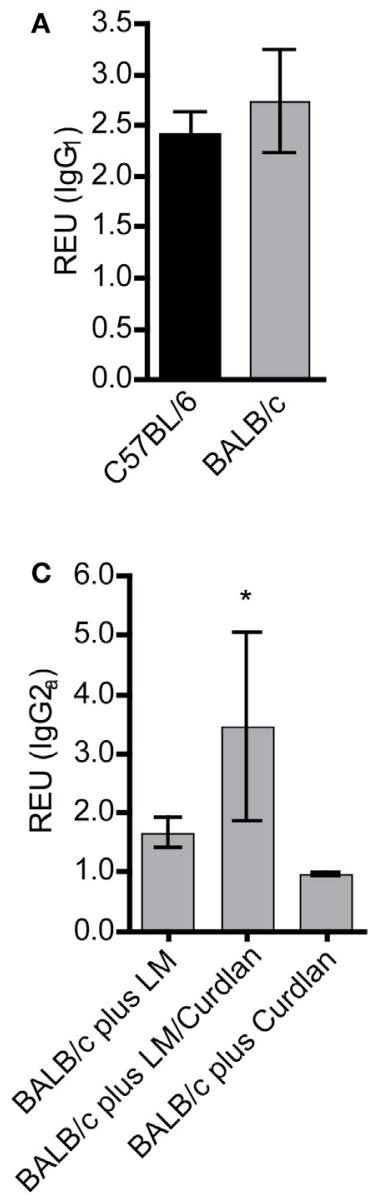
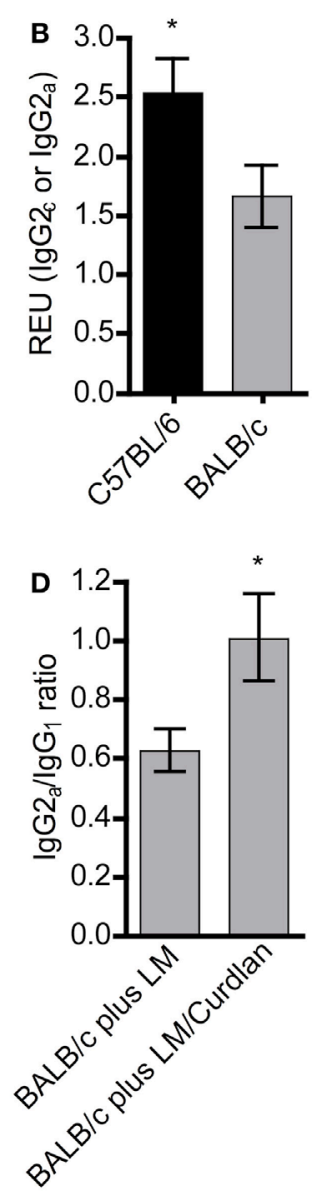

FIGURE 4 | The presence of Curdlan at the site of infection modulates the humoral immune response of BALB/c mice toward a pronounced production of Leishmania-specific IgG2a. C57BL/6 and BALB/c mice were infected with a volume of $30 \mu \mathrm{L}$ PBS containing $3 \times 10^{6}$ Leishmania (L.) major (LM) parasites in the presence or absence of Curdlan $(c=50 \mu \mathrm{g} / \mu \mathrm{L})$. Blood samples were collected 25 days after infection. Leishmania-specific $\lg _{1}$, $\lg _{2 a}$, and $\operatorname{lgG}_{2 \mathrm{c}}$ in sera of infected mice were quantified by ELISA as described in Section "Materials and Methods." (A) Relative ELISA units (REU) of Leishmania-specific lgG $\mathrm{G}_{1}$ of infected BALB/c and C57BL/6 mice are depicted $(n=3)$. (B) REU of Leishmania-specific $\lg _{2 a}$ and $\lg _{2 \mathrm{c}}$ of infected BALB/c and C57BL/6 mice were compared ( $n=3$; $\left.{ }^{*} p<0.05\right)$. (C) REU of Leishmania-specific $\operatorname{lgG}_{2 a}$ of three groups are shown: infected BALB/c mice (plus LM), infected BALB/c mice in the presence of Curdlan (plus LM/ Curdlan), and Curdlan-treated BALB/c mice (plus Curdlan) ( $n=3$; ${ }^{\star} p=0.043$ ). (D) The ratio of Leishmania-specific $\operatorname{lgG}_{2 a} / \operatorname{lgG}_{1}$ was calculated in BALB/c mice infected with L. major (plus LM) and BALB/c mice infected with L. major in the presence of Curdlan (plus LM/Curdlan) $\left(n=3\right.$; $\left.{ }^{*} p<0.05\right)$. Data were analyzed using the non-parametric Mann-Whitney test. The mean $\pm \mathrm{SD}$ is displayed.

To address the question, whether protected BALB/c mice show a Th1 or Th2 profile, $\mathrm{CD} 4^{+} \mathrm{T}$ cells were purified from SDLNs and analyzed by qRT-PCR. It is commonly accepted that activated $\mathrm{CD}^{+} \mathrm{T}$ cells that receive $\mathrm{IL}-4$ signaling upregulate GATAbinding protein 3 (GATA3) and become capable of producing Th2 cytokines $(81,82)$. Thus, GATA3 is regarded as an inducer for Th2-cell differentiation (83).

We measured the relative expression of GATA3 in $\mathrm{CD}^{+}$ $\mathrm{T}$ cells isolated from SDLNs of infected BALB/c mice. These qRTPCR data revealed that Curdlan treatment results in a dampened expression of GATA3 at day 10 (Figure S8A in Supplementary Material), which is significantly reduced at day 28 (Figure S8C in Supplementary Material) after infection compared to control animals. Furthermore, four out of five Curdlan-treated BALB/c mice also showed a clear reduction in IL-4 expression within the pool of CD4 ${ }^{+} \mathrm{T}$ cells (Figures S8B,D in Supplementary Material). Thus, a cutaneous application of Curdlan seems to dampen an early IL-4 production within SDLNs. Surprisingly, CD4 ${ }^{+} \mathrm{T}$ cells isolated from SDLN of Curdlan-treated mice showed a transient trend toward a lower expression of the key transcription factor T-bet, known to define Th1 cells (84), and of the Th1 cytokine IFN- $\gamma$ at day 10 after infection (Figures S8E,F in Supplementary Material). In contrast, at day 28 the expression of T-bet (Figure S8 in Supplementary Material) but not of IFN- $\gamma$ (Figure S8H in Supplementary Material) was slightly increased in $\mathrm{CD}^{+} \mathrm{T}$ cells of Curdlan-treated BALB/c mice.

A rich body of literature described the fact that Th-cell responses are characterized by the balance of Th1- and Th2associated cytokines and not by the relative amount of single cytokines such as IFN- $\gamma$ and IL-4 (85-90). Consequently, we calculated the Th1/Th2 ratio based on the relative expression levels of GATA3, IL-4, T-bet, and IFN- $\gamma$ at days 10 and 28 after infection. As shown in Figures 5A,B, cutaneous Curdlan application was associated with a modulation of the IFN-/IL- 4 ratios at day 10 and 28, indicating a shift toward a pronounced Th1 and a dampened Th2 response at day 28 after infection (Figure 5C). The IFN-/IL-4 ratios of BALB/c mice, infected in the absence of Curdlan showed no modification (Figure 5D). In line with this findings, the ratios of Th1-, Th2-driving transcription factors (T-bet/GATA3) was not substantial different at day 10 but significant enhanced at day 28 (Figures 5E,F), if mice had been treated with Curdlan. Additionally, we were able to demonstrate that this Curdlan-induced Th1 polarization increased from day 10 to day 28 after infection (Figure 5G). T-bet/GATA3ratios of BALB/c mice, infected in the absence of Curdlan showed no modification (Figure 5H). The Th1 polarization was also accompanied by a pronounced IL-17A mRNA expression of $\mathrm{CD} 4^{+} \mathrm{T}$ cells (data not shown).

\section{L. major-Harboring DCs Express Higher Levels of Dectin-1 and Start to Mature after Curdlan Stimulation}

As shown earlier, Dectin-1+ DCs expand at the site of infection and within SDLNs after infection with Leishmania parasites (Figure 2). A dermal exposure to Curdlan can protect BALB/c mice from severe leishmaniasis and induces $\mathrm{T}$ cell-mediated immune responses protecting from a high-dose reinfection (Figure 3). Cutaneous DCs are known to be crucial for the generation of adaptive immunity. These professional APCs capture parasites or parasite-derived antigens and are able to migrate to SDLNs for subsequent antigen presentation to T cells (14). To accomplish these tasks, DCs undergo a maturation program accompanied by the expression of surface molecules pivotal for 

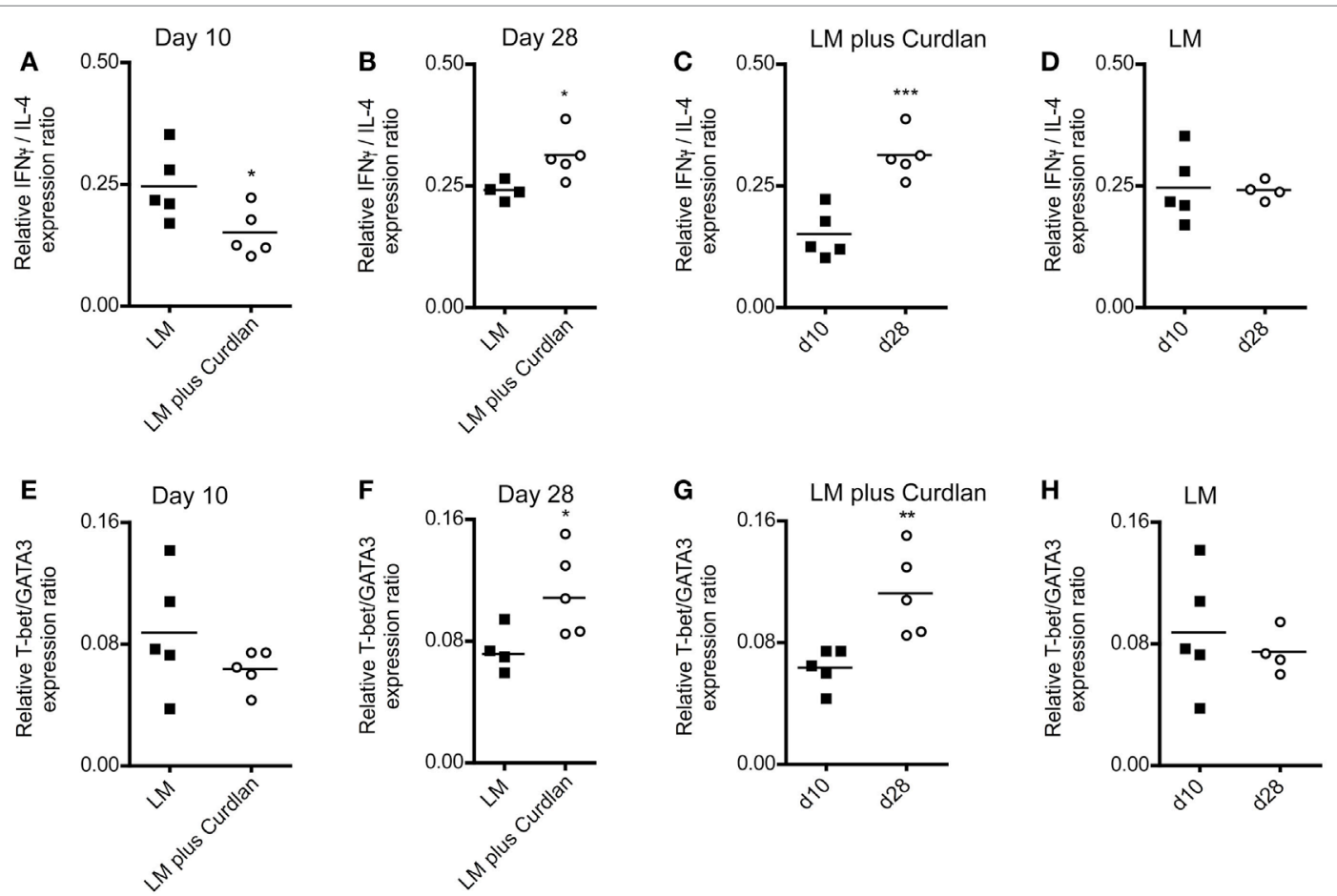

FIGURE 5 | Lymph node-resident CD4+ T cells from Curdlan-treated BALB/c mice show a shift toward an impaired T helper (Th) 2 response. BALB/c mice were infected with a volume of $30 \mu \mathrm{L}$ PBS containing $3 \times 10^{6}$ Leishmania (L.) major (LM) parasites in the presence (abbreviated as $\mathrm{LM}$ plus Curdlan, $C=50 \mu \mathrm{g} / \mathrm{\mu L}$ ) or absence of Curdlan (abbreviated as $L M$ ). $C D 4^{+} T$ cells were purified at days 10 and 28 after infection, and QRT-PCR was performed to determine the relative mRNA levels of target genes referred to GAPDH. The ratios of T-bet/GATA-binding protein 3 (GATA3) and of IFN- $\gamma / \mathrm{LL}-4$ relative mRNA levels are shown. (A,B) The scatter plots depict the relative expression ratio of IFN- $\gamma / \mathrm{LL}-4$ from the analyzed groups (LM and LM plus Curdlan) at day 10 [(A), $\left.{ }^{*} p=0.042\right]$ and day 28 [(B), $\left.{ }^{*} p=0.032\right]$.

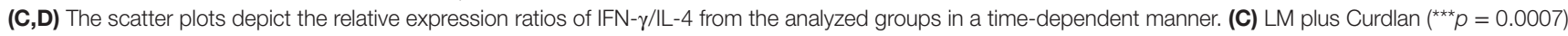
and (D) plus $L M(p>0.05)$. (E,F) The scatter plots depict the relative expression ratio of T-bet/GATA3 from the analyzed groups (LM and LM plus Curdlan). Day 10 $[(\mathbf{E}), p>0.05]$ and day $28\left[(\mathbf{F}),{ }^{*} p=0.048\right]$ are shown. $(\mathbf{G}, \mathbf{H})$ The scatter plots depict the relative expression ratios of T-bet/GATA3 from the analyzed groups in a time-dependent manner. (G) $L M$ plus Curdlan $\left({ }^{* *} p=0.008\right)$ and (D) plus $L M$. Data were analyzed using Student's $t$-test. Each symbol represents an individual mouse, and the bars indicate the medians.

migration and of costimulatory molecules (17). Thus, we wanted to find out whether Dectin-1+ DCs get infected by parasites and if these parasite-harboring Dectin-1 $1^{+}$DCs undergo maturation after Curdlan treatment.

BMDCs were cocultured with CFSE-labeled promastigote parasites. This allows the differentiation of infected versus non-infected BMDCs subsets simultaneously (Figure 6A) (57). With this method, we could demonstrate that L. major ${ }^{+}$BMDCs express a higher level of Dectin-1 compared to uninfected DCs (Figures 6B,C). The frequency of Dectin-1-positive BMDCs was also significantly higher in the infected BMDC population compared to BMDCs that were negative for L. major parasites (Figure 6D). Comparable to BMDCs, BMDMs show also a moderate increase in the frequency of Dectin- $1^{+}$cells and Dectin-1 expression intensity after exposition to L. major parasites (Figure S6 in Supplementary Material). This would suggest Dectin-1mediated host pathogen interactions. Thus, we addressed the question whether pathogen-derived carbohydrates can interact with C-type lectins and especially with Dectin-1.

The CLRs DC-SIGN (CD209) and the mannose receptor C-type 1 (CD206) (91) have been shown to bind Leishmania antigens. However, it is unknown whether Dectin-1 recognizes
L. major-derived molecules. With the help of selected CLR-Fc fusion proteins, we were able to demonstrate an interaction of L. major parasites with CLEC-9 and MGL-1 that recognizes f-actin (92) or galactose, respectively (93) (Figure S9 in Supplementary Material). However, a binding of Dectin-1-Fc fusion proteins to parasite structures could not be observed (Figure S9 in Supplementary Material). Consequently, even though myeloid cells such as macrophages and DCs are positive for Dectin-1 and show a higher Dectin-1 expression after parasite exposition, Dectin-1 alone is not crucial for the uptake of $L$. major parasites, because the parasites are negative for the Dectin-1 ligand. The fact that Dectin- $1^{-/-}$phagocytes can still take up parasites supports that conclusion (31).

L. major parasites can be detected preferentially in BMDCs showing an immature phenotype (Figures 7A,B) and do not induce a maturation of infected cells (data not shown). Thus, parasites seem to inhibit the maturation of immature and Dectin- $1^{\text {high }}$ DCs and thereby the subsequent migration to the $\operatorname{SDLN}(94,95)$. The incubation of infected BMDCs with Curdlan is accompanied by a strong release of TNF- $\alpha$ and IL- 6 and a maturation of infected BMDCs (Figure 7C; Figure S10 in Supplementary Material). This is of special interest, because TNF- $\alpha$ and IL- 6 are known to be 

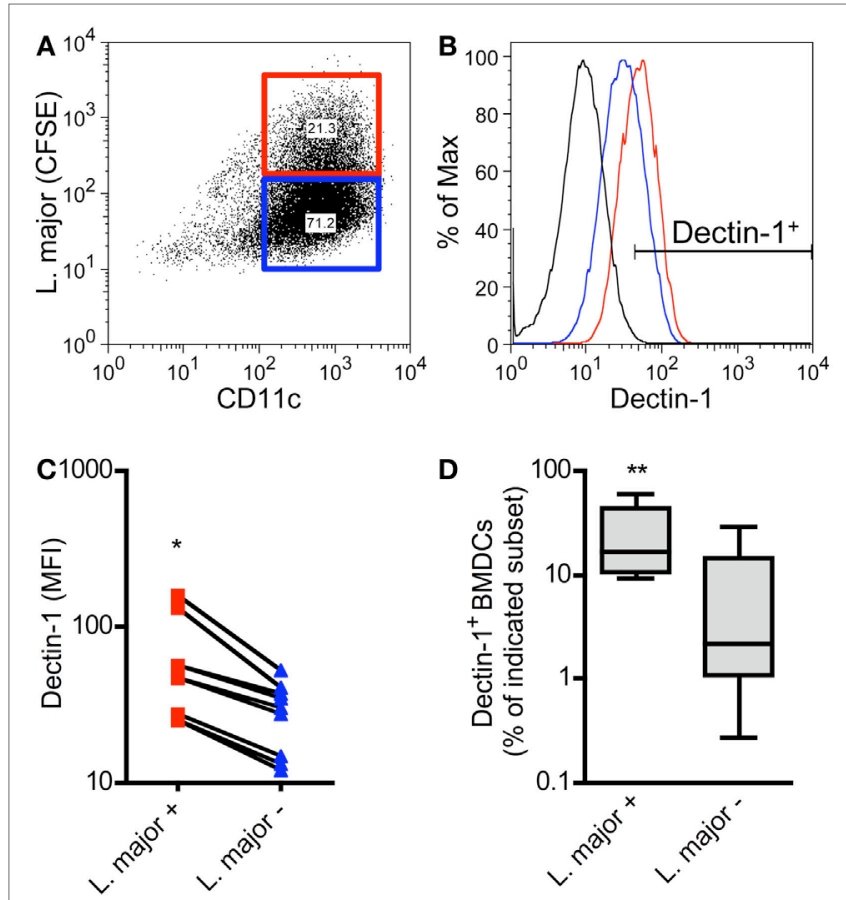

FIGURE 6 | Dectin-1 is expressed to a stronger degree by Leishmania (L.) major harboring bone marrow-derived dendritic cells (BMDCs) compared to non-infected BMDCs. BMDCs were infected with CFSE-labeled L. major promastigote parasites. After $24 \mathrm{~h}$, BMDCs were harvested and characterized by flow cytometry analysis for the markers CD11c and Dectin-1. (A) The dot plot diagram depicts two populations of $L$. major harboring (L. major CFSE+; red square) and not infected (L. major CFSE-; blue square) $\mathrm{CD} 11 \mathrm{C}^{+} \mathrm{BMDCs}$. The gates were placed according to the isotype controls of not infected BMDCs. (B) The histogram visualizes the expression of Dectin-1 of infected (L. major+; red line) and not infected (L. major; blue line) BMDCs. The black line depicts the isotype control. (C) The mean fluorescence intensity (MFI) of Dectin-1 expressed by L. major ${ }^{+}$ (red squares) and not infected subsets (L. major-; blue triangles) is shown. Each symbol represents an individual mouse. Pooled data of three independent experiments are included ( $\left.{ }^{*} p=0.018\right)$. (D) The frequency of Dectin- $1^{+}$cells within the infected (L. major ${ }^{+}$) and not infected (L. major $)$ subsets is displayed as a box plot $\left(n=5\right.$ experiments, $\left.{ }^{* *} p=0.0029\right)$. Data were analyzed using the non-parametric Mann-Whitney test.

crucial for DC maturation and subsequent priming of T cells $(17,18)$. Based on the cytokine microenvironment, infected and non-infected Curdlan-treated BMDCs express high levels of CD86 and thus present a mature phenotype (Figures 7D,E). The stimulation of infected BMDCs with Curdlan also induces a strong release of T-cell growth factor IL-2 (Figure S10 in Supplementary Material). In association with the massive induction of costimulatory molecules such as CD86, Curdlan seems to represent an ideal adjuvant for efficient priming of $L$. major-specific T cells (96). In line with other published data, we showed that Curdlan activates BMDC maturation in a Dectin-1-specific manner (Figure S11 in Supplementary Material) $(97,98)$.

Additionally, we addressed the question whether Dectin-1 can be detected on Curdlan-activated BMDCs. In this context, we were able to demonstrate that immature BMDCs show in general a higher Dectin-1 expression compared to mature BMDCs
(Figure S12A in Supplementary Material), and the detection of surface Dectin-1 is diminished after Curdlan stimulation (Figures S12B,E in Supplementary Material). The population of mature BMDCs, that is positive for L. major parasites, shows also a reduction in the Dectin-1 expression after stimulation with Curdlan (compare Q2, Figure S13 in Supplementary Material). BMDCs that have been exposed to parasites but do not harbor parasites, show no substantial reduction in Dectin-1 expression (compare Q2, Figure S13 in Supplementary Material).

In conclusion, we were able to demonstrate that Curdlan activation results in a maturation of infected BMDCs in a Dectin1 -specific manner that in turn might be crucial for the efficient priming of antigen-specific $\mathrm{CD} 4^{+} \mathrm{T}$ cells.

\section{Curdlan-Activated DCs Show a Pronounced Potential of Expanding Leishmania-Specific CD4 ${ }^{+}$T Cells}

The adjuvant effect of Dectin-1 ligation in T-cell immunity is undisputed, and it has been proven that Curdlan can polarize T-cell responses $(99,100)$. In line with these data, it has been shown that anti-Dectin-1 stimulation and the application of microparticulate $\beta$-glucan conjugates can potentiate an ovalbumin-specific $\mathrm{CD}^{+}$ T-cell response $(101,102)$. It was also described that Curdlan treatment can switch a Th2 to a Th1 response in tumor immunology (103). Last but not least, Dectin-1 ligation is discussed to be an important checkpoint in Th17-mediated immunity $(28,34,38$, $97,104)$. However, the potential of Curdlan to accelerate the expansion of $L$. major-specific CD4 ${ }^{+} \mathrm{T}$ cells has not been described yet. Thus, we isolated $\mathrm{CD} 4^{+} \mathrm{T}$ cells from SDLN of infected BALB/c mice 10 days after infection. BMDCs were pulse-infected with L. major parasites and incubated in the presence or absence of Curdlan. The incubation of $\mathrm{CD}^{+} \mathrm{T}$ cells with Curdlan-activated BMDCs resulted in a mild $\mathrm{CD}^{+} \mathrm{T}$ cell proliferation (Figures 8A,D). Proliferation of $\mathrm{CD}^{+} \mathrm{T}$ cells was substantially increased if BMDCs were pulsed with L. major parasites (Figures 8B,D). A pronounced enhancement of $\mathrm{CD} 4^{+} \mathrm{T}$ cell proliferation was achieved by activating L. major-infected BMDCs with Curdlan (Figures 8C,D). Consequently, Curdlan is capable of triggering the antigen-specific expansion of $\mathrm{CD}^{+} \mathrm{T}$ cells by infected BMDCs in a Dectin-1 specific manner (Figure S14 in Supplementary Material). Our data are in line with other experimental models showing that a Curdlan-induced priming of T cells depends on the Dectin-1 pathway (29). Curdlan also enhances the priming of antigen-specific T-cells by BMDCs exposed to Leishmania antigens (Figure S15 in Supplementary Material).

Supernatants of restimulated $\mathrm{T}$ cells were characterized by Multiplex analysis, to determine the expanded Th-cell subset. We could show that Curdlan treatment results in a 10 -fold pronounced release of IFN- $\gamma$, IL-17, and IL-22 compared to control mice (Figure S16 in Supplementary Material). Thus, we conclude that Curdlan treatment induces a Th1 response in BALB/c mice that overlaps with a co-expression of Th17 cytokines (Figure S16 in Supplementary Material). Of note, the release of Th2 cytokines is not substantially modified (Figure S16 in Supplementary Material). 

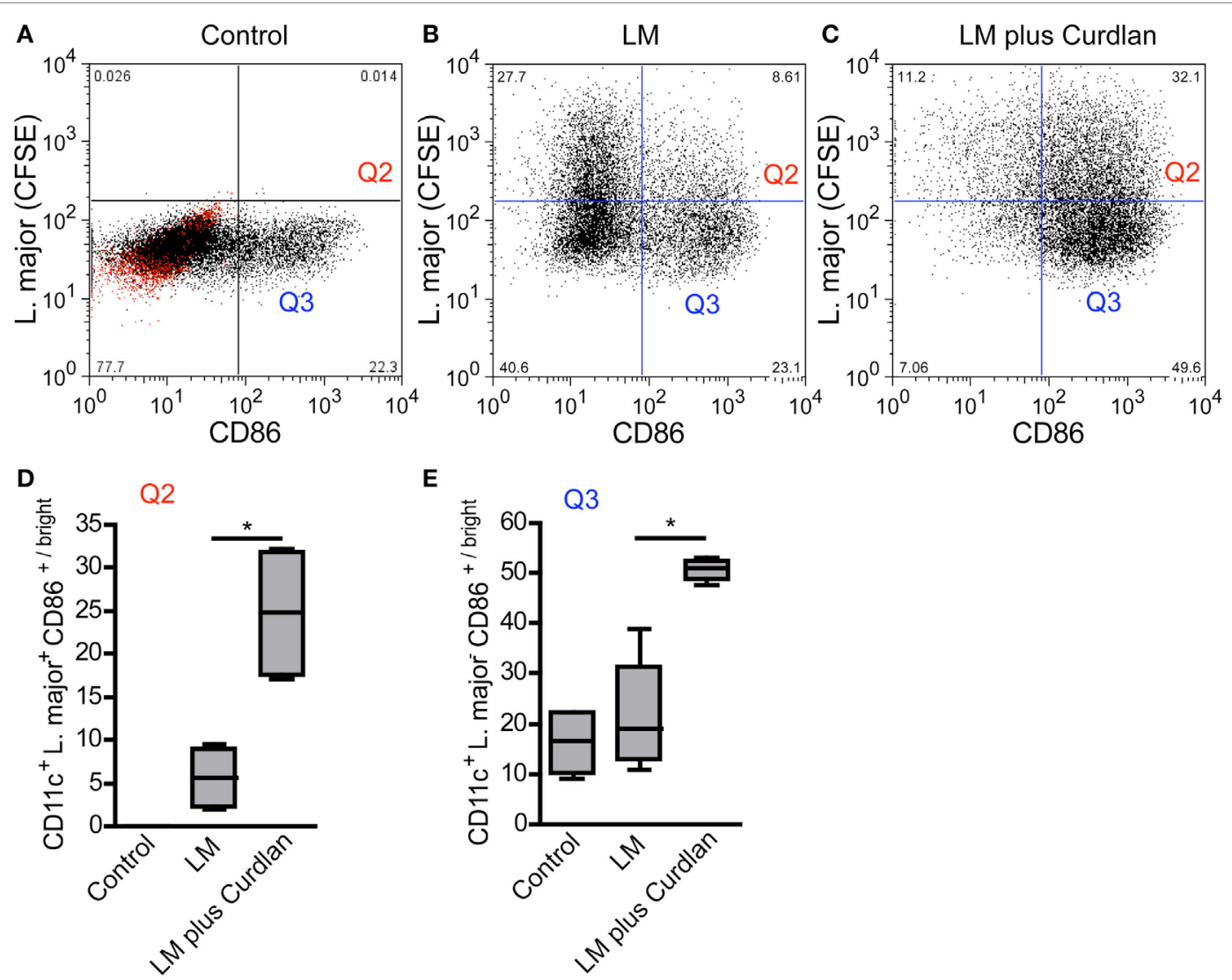

FIGURE 7 | Leishmania (L.) major (LM) harboring bone marrow-derived dendritic cells (BMDCs) mature after Curdlan stimulation. The effect of Curdlan on BMDC maturation was analyzed. $24 \mathrm{~h}$ after the Curdlan stimulation, BMDCs were harvested and characterized by flow cytometry using the markers CD11c and CD86. (A) The dot plot diagram depicts CD11C+ BMDCs that had been cultured in the absence of Curdlan and CFSE-labeled L. major promastigote (control). The red population indicates the isotype control for the anti-CD86 antibody. The quadrants of interest are upper right (Q2, red; L. major CFSE+/CD86+/oright) and lower right (Q3, blue: L. major CFSE-/CD86+//bright). The quadrants were placed according to the isotype control and CD11C+ BMDCs negative for CFSE-labeled parasites. (B) The dot plot diagram depicts the quadrants of interest of CD11C+ BMDCs incubated with CFSE-labeled parasites (LM). (C) The dot plot diagram depicts the quadrants of interest of Curdlan stimulated CD11C+ BMDCs cocultured with CFSE-labeled parasites (LM plus Curdlan). (D) The frequency of $L$. major $\mathrm{CFSE}^{+}$and CD86 ${ }^{+/ \text {bright }} \mathrm{BMDCs}$ (Q2) is shown. (E) The frequency of $L$. major CFSE ${ }^{-}$and CD86 $6^{+/ \text {oright }}$ (Q3) BMDCs is depicted. The following culture conditions were compared: not infected, not stimulated BMDCs [Control, compare (A)], L. major harboring BMDCs [LM, compare (B)], and L. major harboring BMDCs stimulated with Curdlan [LM plus Curdlan, compare (C)]. The box plots $(\mathbf{D}, \mathbf{E})$ depict pooled data out of two independent experiments $(n=4)$. Data were analyzed using the non-parametric Mann-Whitney test [(C,D), $\left.{ }^{*} p=0.0286\right]$.

\section{A Mixture of $L$. major Antigens and Curdlan Induces a Milder Course of Experimental Leishmaniasis in BALB/c Mice}

In combination with Curdlan, whole parasites might be used as a successful live "vaccine." This immunization protocol protects $\mathrm{BALB} / \mathrm{c}$ mice upon challenge with a high-dose reinfection from severe leishmaniasis (compare Figure 3). Consequently, protected $\mathrm{BALB} / \mathrm{c}$ mice must have developed an adaptive T-cell memory response capable of controlling and eliminating $L$. major parasites (75). We investigated whether vaccination of BALB/c mice with L. major antigens (SLA) in combination with Curdlan might also be a promising approach. We tested the adjuvant potential of Curdlan by vaccinating mice intradermally with a mixture of SLA and Curdlan. 28 days later, mice were challenged by a high dose $\left(3 \times 10^{6}\right)$ of L. major parasites into the contralateral footpad.
Control mice that had received SLA in the absence of Curdlan developed a severe course of leishmaniasis that correlated with massive ulceration (compare Figure 3). These control groups were not protected, and the experiment had to be terminated at day 42 according to the animal health and welfare practices (Figures 9A,B).

These results again confirm the already published data that the simple administration of antigens does not induce protection of leishmaniasis in $\mathrm{BALB} / \mathrm{c}$ mice (105). However, some $\mathrm{BALB} / \mathrm{c}$ mice were partially protected after vaccination with SLA combination with Curdlan (Figure 9A). These mice developed a milder course of disease. Even though footpad swelling was still detectable, the ulceration of lesions was milder and substantially delayed (Figure 9B). Of note, a complete protection as achieved with living parasites could not be induced. The mice with delayed but ensuing mild ulcerations and constant footpad swelling were sacrificed during the monitoring period according 

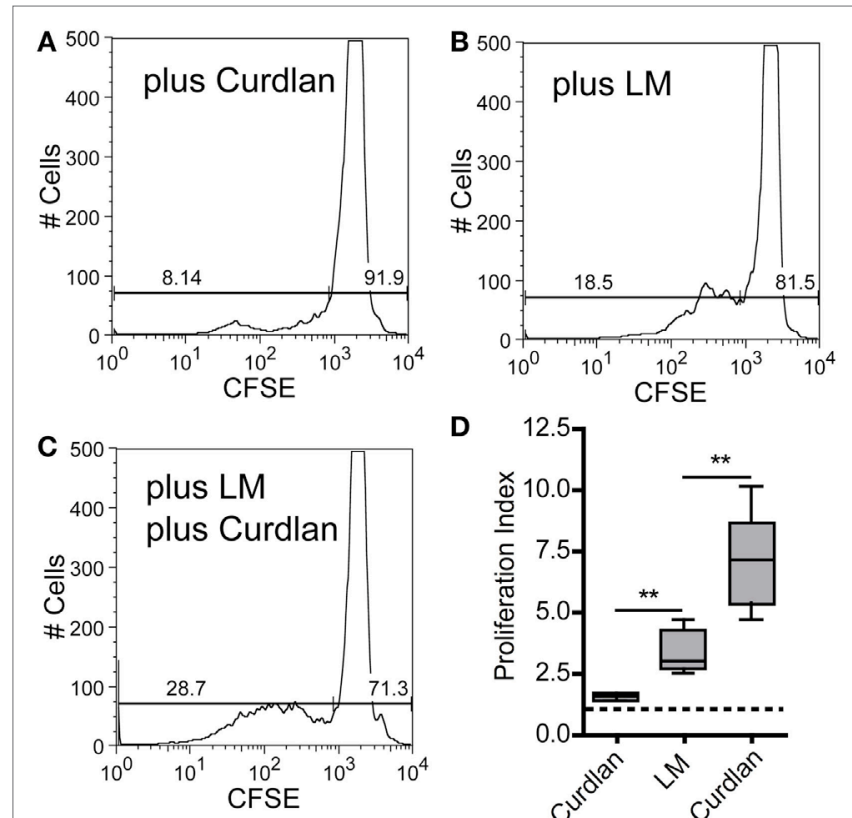

D

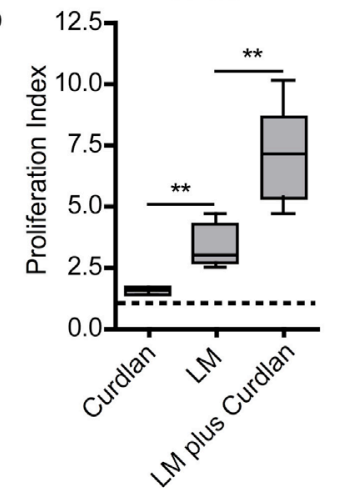

FIGURE 8 | Curdlan stimulation enhances the potential of parasite harboring bone marrow-derived dendritic cells (BMDCs) toward the expansion of Leishmania-specific CD4 ${ }^{+} \mathrm{T}$ cells. BALB/c mice were infected with a volume of $30 \mu \mathrm{L}$ PBS containing $3 \times 10^{6}$ Leishmania (L.) major parasites. Ten days after infection, $\mathrm{CD}^{+} \mathrm{T}$ cells were isolated from skin-draining lymph nodes (SDLNs) and labeled with CFSE. BALB/C BMDCs were harvested at day 10 after ex vivo differentiation with GM-CSF and incubated for $24 \mathrm{~h}$ with $L$. major parasites $(5: 1)$ in the presence or absence of Curdlan $(50 \mu \mathrm{g} / 200 \mu \mathrm{L})$. CFSE-labeled CD3 ${ }^{+} \mathrm{T}$ cells and BMDCs $(10: 1)$ were incubated for $72 \mathrm{~h}$ and analyzed by flow cytometry. The proliferative (left gate) and resting (right gate) $\mathrm{CD}^{+} \mathrm{T}$ cells are visualized by gates within the histogram plots. Following experimental approaches are displayed: (A) Curdlan activated but not infected BMDCs (plus Curdlan), (B) infected but not activated BMDCs (plus L. major), and (C) Curdlan-activated and infected BMDCs (plus L. major; plus Curdlan). The percentage of resting and proliferating cells is indicated inside the corresponding gates. (D) The proliferation index (described in detail in Section "Materials and Methods") is displayed as a box plot diagram. Pooled data from two independent experiments are shown. Data were analyzed using Student's $t$-test (Curdlan compared with LM, ${ }^{* *} P=0.0018$ and LM plus Curdlan compared with LM, $\left.{ }^{\star *} p=0.0058 ; n=5\right)$.

to the guidelines for the care and use of experimental animals (Figure 9B). All analyzed lesions showing a delayed ulceration also exhibited a high parasite load $\left(\mathrm{RPU}>1 \times 10^{8}\right)$.

\section{DISCUSSION}

Already in 1970 s, $\beta$-glucans were used prophylactically or therapeutically in various infectious models of obligatory intracellular pathogens such as Mycobacterium leprae and Plasmodium berghei (106). Since $\beta$-glucans have no direct toxic effect on the named microbes, it has been suggested that a non-specific activation of the reticuloendothelial system was responsible for pathogen elimination (106). In experimental VL, $\beta$-glucans also elicited a strong but non-specific resistance against $L$. donovani in hamsters

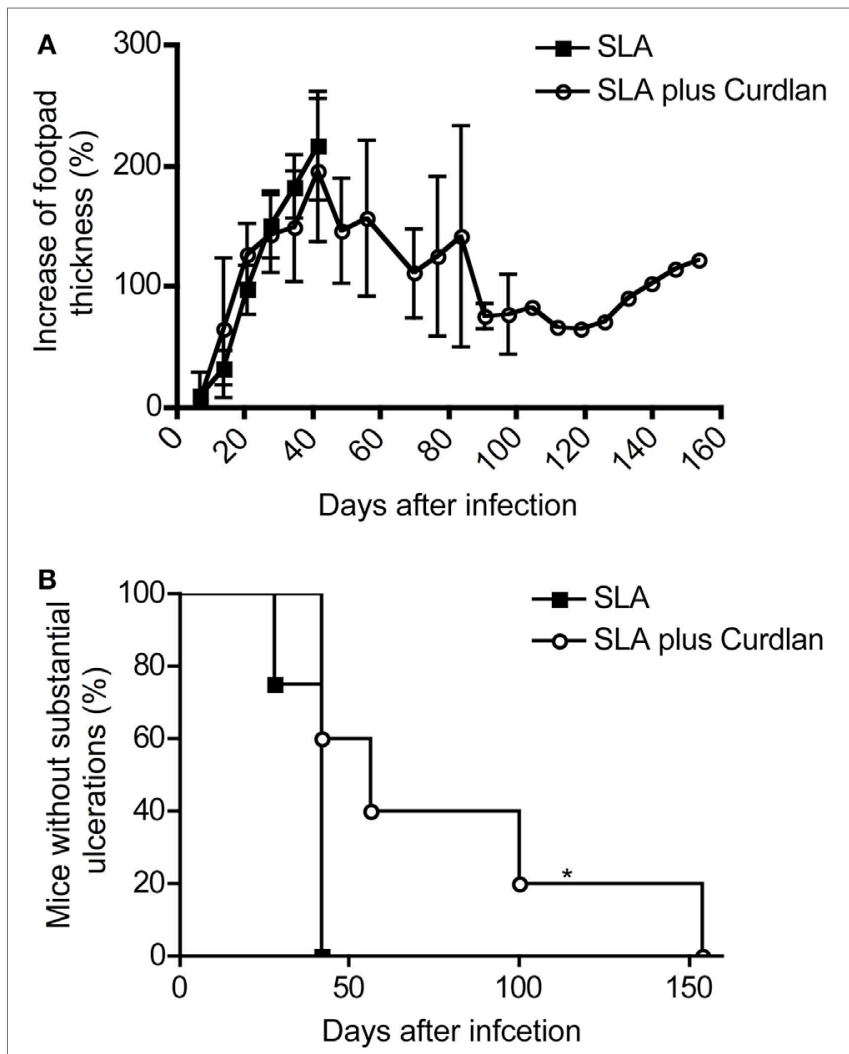

FIGURE 9 | Course of disease in vaccinated mice challenged with Leishmania (L.) major. Soluble L. major antigens (SLA, black square) or SLA plus Curdlan (black circle) treated were injected intradermally into the left footpad of BALB/c mice. The contralateral right footpad was used for the intradermal infection with $3 \times 10^{6} \mathrm{~L}$. major parasites 28 days later. (A) The increase in footpad thickness after infection is shown (mean $\pm \mathrm{SD} ; n=11$ per group). (B) The number of mice that do not develop substantial ulcerations after intradermal infection into the contralateral hind footpad is depicted $\left(n=11 ;{ }^{*} p=0.017\right)$. Significances were calculated using a log-rank test.

and BALB/c mice $(107,108)$. Other groups also demonstrated that an i.v. immunization with $\beta$-glucans combined with killed parasites induced a reduction in the parasite load in visceral organs of BALB/c and C57BL/6 mice $(46,109)$ and that CF-1 mice developed a milder course of VL, if they had been pretreated s.c. or i.v. with $\beta$-glucans in combination with killed $L$. donovani parasites $(43,110)$. These immunization experiments demonstrate that a combination of dead parasites and $\beta$-glucans supports the development of a protective host response in VL. A therapeutic effect of the $\beta$-glucan Curdlan has also been reported in L. donovani (MHOM/IN/1983/AG83)-infected BALB/c mice, in association with the generation of Th17 and Th1 cytokines if systemically (i.p.) treated with Curdlan (34).

In contrast to VL mouse models, the biological impact of $\beta$-glucans seems to be heterogeneous in experimental CL. For instance, a systemic application (i.v.) of $\beta$-glucans was not sufficient to modulate the immune response of $\mathrm{C} 57 \mathrm{BL} / 6$ mice infected with various Leishmania species such as L. mexicana, L. braziliensis, and L. garnhami (45). On the other hand, L. major (MHOM/IL/80/Fredlin)-infected BALB/c mice develop 
a milder course of disease after multiple systemic applications (i.v. or i.p.) of $\beta$-glucans post infection (48). In line with the therapeutic potential of Curdlan, (i.p.) pretreatment with $\beta$-glucans dampened the spreading of $L$. major (HOM/SA/1983/SAYED) parasites in visceral organs of BALB/c mice (111). However, the effects of dermal applied $\beta$-glucans on the generation of adaptive T-cell responses had not been analyzed in detail.

In 2001, the CLR Dectin-1 was identified as the receptor for $\beta$-glucans (23). Subsequently, macrophages and professional antigen-presenting cells were identified as the most prominent cell subsets positive for Dectin-1 $(112,113)$. This finding raised the possibility that the activation of Dectin- $1^{+}$DC subsets during acquisition of adaptive immunity might be modulated by Dectin1-dependent pathways. Based on the current model, Langerin ${ }^{-}$ dermal DCs are pivotal for the induction of the protective Th1-mediated immune response against L. major in experimental leishmaniasis $(13,15,16)$. Thus, the precise conditioning of those DC subsets by Dectin-1-mediated signals might be crucial for the induction of adaptive immunity against Leishmania parasites. However, it is not known whether a cutaneous infection with Leishmania parasites causes an expansion of Dectin- $1^{+}$DCs in humans or experimental models. Additionally, it was not clear whether Dectin-1 signaling results in a pronounced expansion and polarization of L. major-specific T cells.

We showed that Dectin- $1^{+}$DC subsets expanded in patients suffering from CL. Consistent with other reports, we confirmed that Dectin-1 is expressed on peripheral blood mDCs of EHCs $(27,114)$. Furthermore, we were able to demonstrate that Dectin- $1^{+}$peripheral blood $\mathrm{mDC}$ expand in patients suffering from CL compared to EHCs. Given that such an expansion of DC subsets might also take place at the site of infection and in SDLNs of CL patients, Dectin- $1^{+}$mDCs might represent promising targets for a Curdlan-based immunotherapy or vaccination strategy in humans. This is especially of interest since Dectin- $1^{+}$mDCs are discussed to decrease disease-promoting Th2-type responses (115). In contrast to mDCs, the expression of Dectin- 1 by human pDCs is controversially discussed. Unlike mouse Dectin-1, human Dectin-1 is also expressed on B cells (27). Consequently, an expression of Dectin-1 on lymphoid cell subsets is quite conceivable. Indeed, it was demonstrated by Western blot analysis that Dectin-1 is expressed by human $\mathrm{CD}_{303^{+}}$(BDCA2) pDCs (116), whereas in another study CD303 (BDCA2) ${ }^{+}$pDCs were reported mostly negative for Dectin-1 (117). It can be concluded that the frequency of Dectin- $1^{+}$DCs is higher within mDCs compared to pDCs. In line with these data, we could detect Dectin-1 on a small population of $\mathrm{Lin}^{-} / \mathrm{CD} 11 \mathrm{c}^{-} / \mathrm{CD} 123^{+} \mathrm{pDCs}$ within the blood of EHCs and patients suffering from CL. Nevertheless, this extremely small population did not expand after infection. This is important for a Dectin-1 ligand-based vaccination or therapy because $\mathrm{pDC}$ are supposed to favor disease-promoting Th2-type $\mathrm{CD}^{+} \mathrm{T}$ cell responses (118).

Infection with Leishmania parasites is associated with a pronounced myelopoiesis in mammalian hosts $(119,120)$. However, it has not been investigated so far whether this is also accompanied by an expansion of Dectin- $1^{+}$DCs. We show that Dectin- $1^{+} /$ CD $11 \mathrm{c}^{+}$DCs expand within the blood of infected BALB/c and C57BL/6 mice, as in patients suffering from CL. CD11c is hardly expressed by pDCs in mouse models $(71,72)$. Therefore, most CD $11 c^{+/ b r i g h t}$ DCs belong to the subset of conventional DCs including other $\mathrm{mDC}$ subsets but not $\mathrm{pDCs}(73,74)$. In addition, we found a clear increase in Dectin- $1^{+} / \mathrm{CD} 11 \mathrm{c}^{+/ \text {bright }} \mathrm{DCs}$ at the site of infection and SDLNs, proving the concept that Dectin- $1^{+}$DCs represent promising targets for a Curdlan-based immunotherapy.

In vitro analysis was performed to characterize such a potentially beneficial impact of Curdlan/Dectin-1 interactions on DC-mediated priming of $\mathrm{CD}^{+}$Th cells. To accomplish these tasks, DCs must undergo maturation to express surface molecules pivotal for migration such as CCR7 and costimulatory molecules $(14,17)$. Previous studies have already demonstrated that Curdlan can induce DC maturation $(121,122)$, whereas the biological effect of Curdlan on Leishmania-infected DCs was unknown. Parasite harboring DCs show an enhanced Dectin-1 expression but are immature. Curdlan activation resulted in the maturation of parasite-harboring DCs and the release of DC-activating cytokines. Subsequently, Curdlan-primed infected DCs were more potent in expanding antigen-specific $\mathrm{T}$ cells compared to DCs that had not been primed with Curdlan. Of note, Dectin-1 $1^{-/-}$mice (on BALB/c background) were not protected from severe leishmaniasis by dermal Curdlan application. Additionally, Curdlan stimulation could neither mature BMDCs from Dectin- $1^{-/-}$mice nor enhance the priming of antigenspecific $\mathrm{T}$ cells. These findings clearly demonstrate that Dectin-1 is exclusively responsible for the Curdlan-mediated effects in vivo and in vitro. These data are in line with the already published studies, demonstrating a Dectin-1-specific adjuvant effect of Curdlan on T cell priming in other experimental models $(29,98$, 123). Consequently, Dectin-1 ligation can be considered as an important checkpoint for DC maturation and functionality in leishmaniasis.

We would like to point out that surface Dectin-1 is predominantly expressed by immature DC. This explains why infected DCs that in turn display an immature phenotype show a higher Dectin-1 mean fluorescence intensity (MFI) compared to uninfected DCs. Comparable to macrophages, Curdlan-exposed DCs respond with a reduction in the MFI of surface Dectin-1. Whether this reduction is due to the Dectin-1/Curdlan complex internalization, as described for macrophages, is not clear (124). Given the fact that mature DCs in general express lower amounts of surface Dectin-1, it cannot be excluded that maturation of DCs in general is accompanied by the downregulation of surface Dectin-1. In the light of our results, the data from Lima-Junior et al. deserves special consideration. The authors show an enhanced Dectin-1 MFI in L. amazonensis infected macrophages (33). Given the fact that infected and immature DCs display also a higher surface Dectin-1 MFI, it can be suggested that Leishmania parasites might favor preferentially Dectin-1 $1^{+}$myeloid cells. Indeed, Dectin- $1^{-1-}$ phagocytes respond with a moderate reduction in the uptake of L. infantum parasites (31). However, we found that Dectin-1-Fc fusion proteins do not bind to L. major parasites. Thus, a L. major/Dectin-1 interaction can be excluded. This is of crucial importance in three aspects: first, L. major parasites do not induce Dectin-1 signaling-associated maturation of DCs, which might be considered as a smart escape mechanism, preventing DC maturation and subsequent T-cell activation. 
Second, the higher frequency of infected Dectin-1-positive DCs is not the result of L. major Dectin-1 interactions, but might be an upregulation, based on so far not known mechanisms (33). Third, these data might explain the finding that Dectin- $1^{-/}$phagocytes can still phagocyte L. infantum parasites (31).

Apart from these items discussed earlier, Dectin- $1^{+}$mDCs might represent useful targets for the induction of a protective Th1-polarized CD4 ${ }^{+} \mathrm{T}$-cell response by $\beta$-glucans. Indeed, in vivo experiments revealed that a dermal application of Curdlan in the presence of living parasites induced a resistant phenotype in normally susceptible BALB/c mice. It is known that CLR signaling affects macrophage function in experimental leishmaniasis (31). Thus, we had to demonstrate in the high-dose infection model that the Curdlan-mediated effect on protective T-cell immunity was not the result of an early elimination of parasites at the site of infection by dermal macrophages. This would otherwise lead to a substantial reduction in parasite numbers shortly after high-dose infection. This is of crucial importance because low-dose infected $\mathrm{BALB} / \mathrm{c}$ mice can mount a protective Th1 response $(8,125)$. Since the early parasite load at the site of infection was unaltered in the presence of Curdlan, we can exclude Curdlan-mediated early effects on $L$. major clearance by phagocytes. This finding was supported by the fact that Curdlan did not induce leishmanicidal mechanisms in infected macrophages in vitro. Hence, protection in Curdlan-treated $\mathrm{BALB} / \mathrm{c}$ mice is not mediated by unspecific innate immune mechanisms, but an adaptive $\mathrm{T}$ cell-mediated response.

The ratio of Th1/Th2 cell and cytokines is crucial for efficient T cell-mediated immune responses and the outcome of leishmaniasis (86). From our data we can conclude that Curdlan treatment elicits a clear shift toward a protective Th1-mediated response in normally susceptible BALB/c mice. This conclusion is justified because Curdlan-treated $\mathrm{BALB} / \mathrm{c}$ mice developed a resistant phenotype and show a clear DTH response that is associated with the generation of a $\mathrm{T}$ cell memory response, sufficient to protect $\mathrm{BALB} / \mathrm{c}$ mice from a high-dose reinfection (75). The pronounced Leishmania-specific IgG2/IgG1 ratio supports also a manifested Leishmania-specific Th1 response (3). Furthermore, $\mathrm{CD}^{+}{ }^{+} \mathrm{T}$ cells isolated from SDLNs of Curdlan-treated infected BALB/c mice produced a lower level of IL-4 mRNA, but an increased level of cytokines such as IFN- $\gamma$ and TNF- $\alpha$ after antigen-specific restimulation, further supporting a Th1 shift. These data are in line with previous studies, showing that early IL-4/IL-4R interactions promote Th2-cell polarization and impair the development of a Th1 response after infection with $L$. major $(7,85,126-131)$. The enhanced release of IL-22 and IL-17 by CD4 ${ }^{+} \mathrm{T}$ cells of Curdlantreated mice needs a closer view. In mice, IL-17 and IL-22 are preferentially associated with Th17-cell differentiation (132). This is of interest, because the expressions of IL-17 and IL-22 are supposed to be crucial cofactors for Leishmania vaccine-induced immunity (133-136).

Successful vaccination programs against Leishmania parasites are still problematic. However, whole-organism vaccination strategies are most promising $(137,138)$. This implicates that pathogen-associated inflammatory responses at the site of infection might be crucial for the recruitment of appropriate immune cells and the differentiation of antigen-presenting cells, thus resulting in protective immunity $(14,139)$. Whole organisms in combination with Curdlan induce a protective immune response in normally susceptible BALB/c mice. The classical "vaccination" by Leishmania antigens in combination with Curdlan was able to dampen the severe progress of disease. However, full protection could not be achieved. The failure to mount a profound and solid adaptive immunity might be explained by the fact that Leishmania antigens do not persist at the site of infection and do not induce inflammatory immune responses, crucial for driving Th1-mediated adaptive immunity. In conclusion, we propose that whole-organism application in combination with Curdlan represents a promising strategy for the induction of Leishmaniaspecific immunity initiated by Dectin- $1^{+}$DCs.

\section{ETHICS STATEMENT}

Animals: all experiments and animal housing were performed according to the guidelines for the care and use of experimental animals. The animal work was approved by the local veterinary authorities of the district government based on the European guidelines and national regulations of the German Animal Protection Act (approval no. AZ 54-2532.1-05/11). Humans: the sample collection was permitted based on the local ethical committee (allowance number PO25/08, Addis Ababa, Ethiopia) and the national health research ethics review committee (approval number 310/227/07, Addis Ababa). Written informed consent was obtained from the participants of this study.

\section{AUTHOR CONTRIBUTIONS}

$\mathrm{NZ}$ acquired most of the data and analyzed the data. JJ and VS performed the macrophage experiments. MC performed the flow cytometry analysis in Ethiopia, AA, GZ, BL, MS, RW, AR, $\mathrm{AW}$, and GB made substantial contributions to conception of the project and the article. GB and BL contributed materials essential for the work. UR designed the project and drafted and revised the manuscript critically for intellectual content.

\section{ACKNOWLEDGMENTS}

This work was supported by the Priority Program of the German Research Foundation (DFG) (RI 1849/2-1 and 4-1) and the Wellcome Trust (102705). We gratefully acknowledge our Ethiopian partners at the Armauer Hansen Research Institute, Addis Ababa. Rawleigh Howe for excellent supervision of flow cytometry analysis performed at the Armauer Hansen Research Institute and Selfu Girma, Birtukan Endale, Genet Amare and Hareg Yetesh for technical support during the field trips and laboratory work.

\section{SUPPLEMENTARY MATERIAL}

The Supplementary Material for this article can be found online at http://www.frontiersin.org/articles/10.3389/fimmu.2018.00263/ full\#supplementary-material. 


\section{REFERENCES}

1. Dostalova A, Volf P. Leishmania development in sand flies: parasite-vector interactions overview. Parasit Vectors (2012) 5:276. doi:10.1186/17563305-5-276

2. Pace D. Leishmaniasis. J Infect (2014) 69(Suppl 1):S10-8. doi:10.1016/j.jinf. 2014.07.016

3. Sacks D, Noben-Trauth N. The immunology of susceptibility and resistance to Leishmania major in mice. Nat Rev Immunol (2002) 2(11):845-58. doi:10.1038/nri933

4. Solbach W, Bogdan C, Moll H, Lohoff M, Rollinghoff M. [Parasitic evasion mechanisms: Leishmania as an example]. Immun Infekt (1989) 17(4): 129-40.

5. Alexander J, Bryson K. Thelper (h)1/Th2 and Leishmania: paradox rather than paradigm. Immunol Lett (2005) 99(1):17-23. doi:10.1016/j.imlet.2005.01.009

6. Locksley RM, Heinzel FP, Sadick MD, Holaday BJ, Gardner KD Jr. Murine cutaneous leishmaniasis: susceptibility correlates with differential expansion of helper T-cell subsets. Ann Inst Pasteur Immunol (1987) 138(5):744-9. doi:10.1016/S0769-2625(87)80030-2

7. Heinzel FP, Sadick MD, Holaday BJ, Coffman RL, Locksley RM. Reciprocal expression of interferon gamma or interleukin 4 during the resolution or progression of murine leishmaniasis. Evidence for expansion of distinct helper T cell subsets. J Exp Med (1989) 169(1):59-72. doi:10.1084/jem.169.1.59

8. Bretscher PA, Wei G, Menon JN, Bielefeldt-Ohmann H. Establishment of stable, cell-mediated immunity that makes "susceptible" mice resistant to Leishmania major. Science (1992) 257(5069):539-42. doi:10.1126/ science. 1636090

9. Rocken M, Saurat JH, Hauser C. A common precursor for CD4+ T cells producing IL-2 or IL-4. J Immunol (1992) 148(4):1031-6.

10. Abbas AK, Murphy KM, Sher A. Functional diversity of helper T lymphocytes. Nature (1996) 383(6603):787-93. doi:10.1038/383787a0

11. Scott P, Novais FO. Cutaneous leishmaniasis: immune responses in protection and pathogenesis. Nat Rev Immunol (2016) 16(9):581-92. doi:10.1038/ nri.2016.72

12. Moreno J. Changing views on Langerhans cell functions in leishmaniasis. Trends Parasitol (2007) 23(3):86-8. doi:10.1016/j.pt.2007.01.002

13. Brewig N, Kissenpfennig A, Malissen B, Veit A, Bickert T, Fleischer B, et al. Priming of CD8+ and CD4+ T cells in experimental leishmaniasis is initiated by different dendritic cell subtypes. J Immunol (2009) 182(2):774-83. doi:10.4049/jimmunol.182.2.774

14. Ritter U, Osterloh A. A new view on cutaneous dendritic cell subsets in experimental leishmaniasis. Med Microbiol Immunol (2007) 196(1):51-9. doi:10.1007/s00430-006-0023-0

15. Ritter U, Meissner A, Scheidig C, Korner H. CD8 alpha- and Langerin-negative dendritic cells, but not Langerhans cells, act as principal antigen-presenting cells in leishmaniasis. Eur J Immunol (2004) 34(6):1542-50. doi:10.1002/eji. 200324586

16. Kautz-Neu K, Noordegraaf M, Dinges S, Bennett CL, John D, Clausen BE, et al. Langerhans cells are negative regulators of the anti-Leishmania response. J Exp Med (2011) 208(5):885-91. doi:10.1084/jem.20102318

17. Ritter U, Meissner A, Ott J, Korner H. Analysis of the maturation process of dendritic cells deficient for TNF and lymphotoxin-alpha reveals an essential role for TNF. J Leukoc Biol (2003) 74(2):216-22. doi:10.1189/jlb.1202587

18. Park SJ, Nakagawa T, Kitamura H, Atsumi T, Kamon H, Sawa S, et al. IL-6 regulates in vivo dendritic cell differentiation through STAT3 activation. J Immunol (2004) 173(6):3844-54. doi:10.4049/jimmunol.173.6.3844

19. Goldstein DR. Toll-like receptors and other links between innate and acquired alloimmunity. Curr Opin Immunol (2004) 16(5):538-44. doi:10.1016/j.coi. 2004.08.001

20. Akira S, Uematsu S, Takeuchi O. Pathogen recognition and innate immunity. Cell (2006) 124(4):783-801. doi:10.1016/j.cell.2006.02.015

21. Li Y, Li Y, Cao X, Jin X, Jin T. Pattern recognition receptors in zebrafish provide functional and evolutionary insight into innate immune signaling pathways. Cell Mol Immunol (2017) 14(1):80-9. doi:10.1038/cmi.2016.50

22. Zelensky AN, Gready JE. The C-type lectin-like domain superfamily. FEBS J (2005) 272(24):6179-217. doi:10.1111/j.1742-4658.2005.05031.x

23. Brown GD, Gordon S. Immune recognition. A new receptor for beta-glucans. Nature (2001) 413(6851):36-7. doi:10.1038/35092620
24. Mayer S, Raulf MK, Lepenies B. C-type lectins: their network and roles in pathogen recognition and immunity. Histochem Cell Biol (2017) 147(2):223-37. doi:10.1007/s00418-016-1523-7

25. Monteiro JT, Lepenies B. Myeloid C-type lectin receptors in viral recognition and antiviral immunity. Viruses (2017) 9(3):1-58. doi:10.3390/v9030059

26. Chiba S, Ikushima H, Ueki H, Yanai H, Kimura Y, Hangai S, et al. Recognition of tumor cells by Dectin-1 orchestrates innate immune cells for anti-tumor responses. Elife (2014) 3:e04177. doi:10.7554/eLife.04177

27. Taylor PR, Brown GD, Reid DM, Willment JA, Martinez-Pomares L, Gordon S, et al. The beta-glucan receptor, dectin-1, is predominantly expressed on the surface of cells of the monocyte/macrophage and neutrophil lineages. J Immunol (2002) 169(7):3876-82. doi:10.4049/jimmunol.169.7.3876

28. Kashem SW, Igyarto BZ, Gerami-Nejad M, Kumamoto Y, Mohammed J, Jarrett E, et al. Candida albicans morphology and dendritic cell subsets determine T helper cell differentiation. Immunity (2015) 42(2):356-66. doi:10.1016/j. immuni.2015.01.008

29. Leibundgut-Landmann S, Osorio F, Brown GD, Reis e Sousa C. Stimulation of dendritic cells via the dectin-1/Syk pathway allows priming of cytotoxic T-cell responses. Blood (2008) 112(13):4971-80. doi:10.1182/ blood-2008-05-158469

30. Willment JA, Marshall AS, Reid DM, Williams DL, Wong SY, Gordon S, et al. The human beta-glucan receptor is widely expressed and functionally equivalent to murine Dectin-1 on primary cells. Eur J Immunol (2005) 35(5):1539-47. doi:10.1002/eji.200425725

31. Lefevre L, Lugo-Villarino G, Meunier E, Valentin A, Olagnier D, Authier $\mathrm{H}$, et al. The C-type lectin receptors dectin-1, MR, and SIGNR3 contribute both positively and negatively to the macrophage response to Leishmania infantum. Immunity (2013) 38(5):1038-49. doi:10.1016/j. immuni.2013.04.010

32. Veras PS, de Chastellier C, Rabinovitch M. Transfer of zymosan (yeast cell walls) to the parasitophorous vacuoles of macrophages infected with Leishmania amazonensis. J Exp Med (1992) 176(3):639-46. doi:10.1084/jem. 176.3.639

33. Lima-Junior DS, Mineo TWP, Calich VLG, Zamboni DS. Dectin-1 activation during Leishmania amazonensis phagocytosis prompts Syk-dependent reactive oxygen species production to trigger inflammasome assembly and restriction of parasite replication. J Immunol (2017) 199(6):2055-68. doi:10.4049/jimmunol.1700258

34. Ghosh K, Sharma G, Saha A, Kar S, Das PK, Ukil A. Successful therapy of visceral leishmaniasis with curdlan involves T-helper 17 cytokines. J Infect Dis (2013) 207(6):1016-25. doi:10.1093/infdis/jis771

35. Shivahare R, Ali W, Singh US, Natu SM, Khattri S, Puri SK, et al. Immunoprotective effect of lentinan in combination with miltefosine on Leishmania-infected J-774A.1 macrophages. Parasite Immunol (2016) 38(10): 618-27. doi:10.1111/pim.12346

36. Hsieh HJ, Li NQ, Frangos JA. Shear stress increases endothelial plateletderived growth factor mRNA levels. Am J Physiol (1991) 260(2 Pt 2):H642-6.

37. Hardison SE, Brown GD. C-type lectin receptors orchestrate antifungal immunity. Nat Immunol (2012) 13(9):817-22. doi:10.1038/ni.2369

38. Hernandez-Santos N, Gaffen SL. Th17 cells in immunity to Candida albicans. Cell Host Microbe (2012) 11(5):425-35. doi:10.1016/j.chom.2012.04.008

39. Wuthrich M, Deepe GS Jr, Klein B. Adaptive immunity to fungi. Annu Rev Immunol (2012) 30:115-48. doi:10.1146/annurev-immunol-020711074958

40. Carvalho A, Giovannini G, De Luca A, D’Angelo C, Casagrande A, Iannitti RG, et al. Dectin-1 isoforms contribute to distinct Th1/Th17 cell activation in mucosal candidiasis. Cell Mol Immunol (2012) 9(3):276-86. doi:10.1038/ cmi.2012.1

41. Rivera A, Hohl TM, Collins N, Leiner I, Gallegos A, Saijo S, et al. Dectin-1 diversifies Aspergillus fumigatus-specific $\mathrm{T}$ cell responses by inhibiting $\mathrm{T}$ helper type 1 CD4 T cell differentiation. J Exp Med (2012) 208(2):369-81. doi:10.1084/jem.20100906

42. Taylor PR, Tsoni SV, Willment JA, Dennehy KM, Rosas M, Findon H, et al. Dectin-1 is required for beta-glucan recognition and control of fungal infection. Nat Immunol (2007) 8(1):31-8. doi:10.1038/ni1408

43. Holbrook TW, Cook JA, Parker BW. Immunization against Leishmania donovani: glucan as an adjuvant with killed promastigotes. Am J Trop Med Hyg (1981) 30(4):762-8. doi:10.4269/ajtmh.1981.30.762 
44. Holbrook TW, Cook JA. Non-specific and specific stimulation of resistance against Leishmania donovani in C57BL/6 mice. Ann Clin Lab Sci (1983) 13(5):411-7.

45. Avila JL, Biondo F, Monzon H, Convit J. Cutaneous leishmaniasis in mice: resistance to glucan immunotherapy, either alone or combined with chemotherapy. Am J Trop Med Hyg (1982) 31(1):53-9. doi:10.4269/ajtmh.1982.31.53

46. Jarecki-Black JC, James ER, Kirshtein JW, Kirshtein JD, Glassman AB. Leishmania donovani: immunization against infection as a function of parasite growth phase. Am J Trop Med Hyg (1986) 35(6):1117-20. doi:10.4269/ ajtmh.1986.35.1117

47. Runey GL, Jarecki-Black JC, Runey MW, Glassman AB. Antithymocyte serum suppression of immunity in mice immunized to Leishmania donovani. Ann Clin Lab Sci (1990) 20(4):263-7.

48. Goldman R, Jaffe CL. Administration of beta-glucan following Leishmania major infection suppresses disease progression in mice. Parasite Immunol (1991) 13(2):137-45. doi:10.1111/j.1365-3024.1991.tb00270.x

49. Schonian G, Nasereddin A, Dinse N, Schweynoch C, Schallig HD, Presber $\mathrm{W}$, et al. PCR diagnosis and characterization of Leishmania in local and imported clinical samples. Diagn Microbiol Infect Dis (2003) 47(1):349-58. doi:10.1016/S0732-8893(03)00093-2

50. Saijo S, Fujikado N, Furuta T, Chung SH, Kotaki H, Seki K, et al. Dectin-1 is required for host defense against Pneumocystis carinii but not against Candida albicans. Nat Immunol (2007) 8(1):39-46. doi:10.1038/ni1425

51. Solbach W, Forberg K, Rollinghoff M. Effect of T-lymphocyte suppression on the parasite burden in Leishmania major-infected, genetically susceptible BALB/c mice. Infect Immun (1986) 54(3):909-12.

52. Wilhelm P, Ritter U, Labbow S, Donhauser N, Rollinghoff M, Bogdan C, et al. Rapidly fatal leishmaniasis in resistant C57BL/6 mice lacking TNF. J Immunol (2001) 166(6):4012-9. doi:10.4049/jimmunol.166.6.4012

53. Weiss R, Scheiblhofer S, Thalhamer J, Bickert T, Richardt U, Fleischer B, et al. Epidermal inoculation of Leishmania-antigen by gold bombardment results in a chronic form of leishmaniasis. Vaccine (2007) 25(1):25-33. doi:10.1016/j. vaccine.2006.07.044

54. Lutz MB, Kukutsch N, Ogilvie AL, Rossner S, Koch F, Romani N, et al. An advanced culture method for generating large quantities of highly pure dendritic cells from mouse bone marrow. J Immunol Methods (1999) 223(1):77-92. doi:10.1016/S0022-1759(98)00204-X

55. Schleicher U, Bogdan C. Generation, culture and flow-cytometric characterization of primary mouse macrophages. Methods Mol Biol (2009) 531:203-24. doi:10.1007/978-1-59745-396-7_14

56. Schatz V, Strussmann Y, Mahnke A, Schley G, Waldner M, Ritter U, et al. Myeloid cell-derived HIF-1alpha promotes control of Leishmania major. J Immunol (2016) 197(10):4034-41. doi:10.4049/jimmunol.1601080

57. Schmid M, Zimara N, Wege AK, Ritter U. Myeloid-derived suppressor cell functionality and interaction with Leishmania major parasites differ in C57BL/6 and BALB/c mice. Eur J Immunol (2014) 44(11):3295-306. doi:10.1002/eji.201344335

58. Maglinao M,Eriksson M,Schlegel MK,ZimmermannS, Johannssen T, GotzeS, et al. A platform to screen for C-type lectin receptor-binding carbohydrates and their potential for cell-specific targeting and immune modulation. J Control Release (2014) 175:36-42. doi:10.1016/j.jconrel.2013.12.011

59. Schmid M, Dufner B, Durk J, Bedal K, Stricker K, Prokoph LA, et al. An emerging approach for parallel quantification of intracellular protozoan parasites and host cell characterization using TissueFAXS cytometry. PLoS One (2015) 10(10):e0139866. doi:10.1371/journal.pone.0139866

60. Zimara N, Florian C, Schmid M, Malissen B, Kissenpfennig A, Mannel DN, et al. Langerhans cells promote early germinal center formation in response to Leishmania-derived cutaneous antigens. Eur J Immunol (2014) 44(10): 2955-67. doi:10.1002/eji.201344263

61. Ritter U, Lechner A, Scharl K, Kiafard Z, Zwirner J, Korner H. TNF controls the infiltration of dendritic cells into the site of Leishmania major infection. Med Microbiol Immunol (2008) 197(1):29-37. doi:10.1007/ s00430-007-0056-z

62. Aldebert D, Diallo M, Niang M, Sarr D, Cisse C, Moreau JC, et al. Differences in circulating dendritic cell subtypes in peripheral, placental and cord blood in African pregnant women. J Reprod Immunol (2007) 73(1):11-9. doi:10.1016/j.jri.2006.05.002
63. Rascle A, Johnston JA, Amati B. Deacetylase activity is required for recruitment of the basal transcription machinery and transactivation by STAT5. Mol Cell Biol (2003) 23(12):4162-73. doi:10.1128/MCB.23.12.41624173.2003

64. Pinz S, Unser S, Buob D, Fischer P, Jobst B, Rascle A. Deacetylase inhibitors repress STAT5-mediated transcription by interfering with bromodomain and extra-terminal (BET) protein function. Nucleic Acids Res (2015) 43(7):3524-45. doi:10.1093/nar/gkv188

65. Pahl A, Kuhlbrandt U, Brune K, Rollinghoff M, Gessner A. Quantitative detection of Borrelia burgdorferi by real-time PCR. J Clin Microbiol (1999) 37(6):1958-63.

66. Schulz A, Mellenthin K, Schonian G, Fleischer B, Drosten C. Detection, differentiation, and quantitation of pathogenic Leishmania organisms by a fluorescence resonance energy transfer-based real-time PCR assay. J Clin Microbiol (2003) 41(4):1529-35. doi:10.1128/JCM.41.4.1529-1535.2003

67. Feijo D, Tiburcio R, Ampuero M, Brodskyn C, Tavares N. Dendritic cells and Leishmania infection: adding layers of complexity to a complex disease. J Immunol Res (2016) 2016:3967436. doi:10.1155/2016/3967436

68. MacDonald KP, Munster DJ, Clark GJ, Dzionek A, Schmitz J, Hart DN. Characterization of human blood dendritic cell subsets. Blood (2002) 100(13):4512-20. doi:10.1182/blood-2001-11-0097

69. Ueda Y, Hagihara M, Okamoto A, Higuchi A, Tanabe A, Hirabayashi K, et al Frequencies of dendritic cells (myeloid DC and plasmacytoid DC) and their ratio reduced in pregnant women: comparison with umbilical cord blood and normal healthy adults. Hum Immunol (2003) 64(12):1144-51. doi:10.1016/j. humimm.2003.08.342

70. Robinson SP, Patterson S, English N, Davies D, Knight SC, Reid CD. Human peripheral blood contains two distinct lineages of dendritic cells. Eur J Immunol (1999) 29(9):2769-78. doi:10.1002/(SICI)1521-4141(199909) 29:09<2769:AID-IMMU2769>3.0.CO;2-2

71. Merad M, Sathe P, Helft J, Miller J, Mortha A. The dendritic cell lineage: ontogeny and function of dendritic cells and their subsets in the steady state and the inflamed setting. Annu Rev Immunol (2013) 31:563-604. doi:10.1146/ annurev-immunol-020711-074950

72. Reizis B, Bunin A, Ghosh HS, Lewis KL, Sisirak V. Plasmacytoid dendritic cells: recent progress and open questions. Annu Rev Immunol (2011) 29:163-83. doi:10.1146/annurev-immunol-031210-101345

73. Asselin-Paturel C, Brizard G, Pin JJ, Briere F, Trinchieri G. Mouse strain differences in plasmacytoid dendritic cell frequency and function revealed by a novel monoclonal antibody. J Immunol (2003) 171(12):6466-77. doi:10.4049/ jimmunol.171.12.6466

74. Schraml BU, Reis e Sousa C. Defining dendritic cells. Curr Opin Immunol (2015) 32:13-20. doi:10.1016/j.coi.2014.11.001

75. Glennie ND, Scott P. Memory T cells in cutaneous leishmaniasis. Cell Immunol (2016) 309:50-4. doi:10.1016/j.cellimm.2016.07.010

76. Zaph C, Uzonna J, Beverley SM, Scott P. Central memory T cells mediate long-term immunity to Leishmania major in the absence of persistent parasites. Nat Med (2004) 10(10):1104-10. doi:10.1038/nm1108

77. Liew FY. Functional heterogeneity of CD4+ T cells in leishmaniasis. Immunol Today (1989) 10(2):40-5. doi:10.1016/0167-5699(89)90302-2

78. Brown DR, Reiner SL. Polarized helper-T-cell responses against Leishmania major in the absence of B cells. Infect Immun (1999) 67(1):266-70.

79. Finkelman FD, Holmes J, Katona IM, Urban JF Jr, Beckmann MP, Park LS, et al. Lymphokine control of in vivo immunoglobulin isotype selection. Annu Rev Immunol (1990) 8:303-33. doi:10.1146/annurev.iy.08.040190.001511

80. Martin RM, Brady JL, Lew AM. The need for IgG2c specific antiserum when isotyping antibodies from C57BL/6 and NOD mice. J Immunol Methods (1998) 212(2):187-92. doi:10.1016/S0022-1759(98)00015-5

81. Kurata H, Lee HJ, O'Garra A, Arai N. Ectopic expression of activated Stat6 induces the expression of Th2-specific cytokines and transcription factors in developing Th1 cells. Immunity (1999) 11(6):677-88. doi:10.1016/ S1074-7613(00)80142-9

82. Zhu J, Guo L, Watson CJ, Hu-Li J, Paul WE. Stat6 is necessary and sufficient for IL-4's role in Th2 differentiation and cell expansion. J Immunol (2001) 166(12):7276-81. doi:10.4049/jimmunol.166.12.7276

83. Zhang DH, Cohn L, Ray P, Bottomly K, Ray A. Transcription factor GATA-3 is differentially expressed in murine Th 1 and Th 2 cells and controls Th2-specific 
expression of the interleukin-5 gene. J Biol Chem (1997) 272(34):21597-603. doi:10.1074/jbc.272.34.21597

84. Kallies A, Good-Jacobson KL. Transcription factor T-bet orchestrates lineage development and function in the immune system. Trends Immunol (2017) 38(4):287-97. doi:10.1016/j.it.2017.02.003

85. Chatelain R, Varkila K, Coffman RL. IL-4 induces a Th2 response in Leishmania major-infected mice. J Immunol (1992) 148(4):1182-7.

86. Scott P, Eaton A, Gause WC, di Zhou X, Hondowicz B. Early IL-4 production does not predict susceptibility to Leishmania major. Exp Parasitol (1996) 84(2):178-87. doi:10.1006/expr.1996.0103

87. Scott P, Hondowicz B, Eaton A, Scharton-Kersten T. The role of IL-12 in regulation of $\mathrm{T}$ helper cell subsets in vivo. Lessons from experimental cutaneous leishmaniasis. Ann N Y Acad Sci (1996) 795:250-6. doi:10.1111/j. 1749-6632.1996.tb52674.x

88. Scharton TM, Scott P. Natural killer cells are a source of interferon gamma that drives differentiation of $\mathrm{CD} 4+\mathrm{T}$ cell subsets and induces early resistance to Leishmania major in mice. J Exp Med (1993) 178(2):567-77. doi:10.1084/ jem.178.2.567

89. Morris L, Troutt AB, Handman E, Kelso A. Changes in the precursor frequencies of IL-4 and IFN-gamma secreting CD4+ cells correlate with resolution of lesions in murine cutaneous leishmaniasis. J Immunol (1992) 149(8):2715-21.

90. Scott P. IFN-gamma modulates the early development of Th1 and Th2 responses in a murine model of cutaneous leishmaniasis. J Immunol (1991) 147(9):3149-55.

91. Geijtenbeek TB, Gringhuis SI. Signalling through C-type lectin receptors: shaping immune responses. Nat Rev Immunol (2009) 9(7):465-79. doi:10.1038/nri2569

92. Ahrens S, Zelenay S, Sancho D, Hanc P, Kjaer S, Feest C, et al. F-actin is an evolutionarily conserved damage-associated molecular pattern recognized by DNGR-1, a receptor for dead cells. Immunity (2012) 36(4):635-45. doi:10.1016/j.immuni.2012.03.008

93. van Kooyk Y, Ilarregui JM, van Vliet SJ. Novel insights into the immunomodulatory role of the dendritic cell and macrophage-expressed C-type lectin MGL. Immunobiology (2015) 220(2):185-92. doi:10.1016/j. imbio.2014.10.002

94. Ponte-Sucre A, Heise D, Moll H. Leishmania major lipophosphoglycan modulates the phenotype and inhibits migration of murine Langerhans cells. Immunology (2001) 104(4):462-7. doi:10.1046/j.1365-2567.2001.01333.x

95. Schmid M, Wege AK, Ritter U. Characteristics of "Tip-DCs and MDSCs" and their potential role in leishmaniasis. Front Microbiol (2012) 3:74. doi:10.3389/ fmicb.2012.00074

96. Granucci F, Vizzardelli C, Pavelka N, Feau S, Persico M, Virzi E, et al. Inducible IL-2 production by dendritic cells revealed by global gene expression analysis. Nat Immunol (2001) 2(9):882-8. doi:10.1038/ni0901-882

97. LeibundGut-Landmann S, Gross O, Robinson MJ, Osorio F, SlackEC, TsoniSV, et al. Syk- and CARD9-dependent coupling of innate immunity to the induction of T helper cells that produce interleukin 17. Nat Immunol (2007) 8(6):630-8. doi:10.1038/ni1460

98. Yoshitomi H, Sakaguchi N, Kobayashi K, Brown GD, Tagami T, Sakihama T, et al. A role for fungal \{beta\}-glucans and their receptor Dectin-1 in the induction of autoimmune arthritis in genetically susceptible mice. J Exp Med (2005) 201(6):949-60. doi:10.1084/jem.20041758

99. Lemoine S, Jaron B, Tabka S, Ettreiki C, Deriaud E, Zhivaki D, et al. Dectin-1 activation unlocks IL12A expression and reveals the TH1 potency of neonatal dendritic cells. J Allergy Clin Immunol (2015) 136(5):1355-68.e1-15. doi:10.1016/j.jaci.2015.02.030

100. Gringhuis SI, den Dunnen J, Litjens M, van der Vlist M, Wevers B, Bruijns SC, et al. Dectin-1 directs $\mathrm{T}$ helper cell differentiation by controlling noncanonical NF-kappaB activation through Raf-1 and Syk. Nat Immunol (2009) 10(2):203-13. doi:10.1038/ni.1692

101. Carter RW, Thompson C, Reid DM, Wong SY, Tough DF. Preferential induction of $\mathrm{CD} 4+\mathrm{T}$ cell responses through in vivo targeting of antigen to dendritic cell-associated C-type lectin-1. J Immunol (2006) 177(4):2276-84. doi:10.4049/jimmunol.177.4.2276

102. Berner VK, duPre SA, Redelman D, Hunter KW. Microparticulate beta-glucan vaccine conjugates phagocytized by dendritic cells activate both naive CD4 and CD8 T cells in vitro. Cell Immunol (2015) 298(1-2):104-14. doi:10.1016/j.cellimm.2015.10.007
103. Baran J, Allendorf DJ, Hong F, Ross GD. Oral beta-glucan adjuvant therapy converts nonprotective $\mathrm{Th} 2$ response to protective $\mathrm{Th} 1$ cell-mediated immune response in mammary tumor-bearing mice. Folia Histochem Cytobiol (2007) 45(2):107-14.

104. Wang H, LeBert V, Hung CY, Galles K, Saijo S, Lin X, et al. C-type lectin receptors differentially induce th 17 cells and vaccine immunity to the endemic mycosis of North America. J Immunol (2014) 192(3):1107-19. doi:10.4049/jimmunol.1302314

105. Stacey KJ, Blackwell JM. Immunostimulatory DNA as an adjuvant in vaccination against Leishmania major. Infect Immun (1999) 67(8):3719-26.

106. Song M, di Luzio NR. Yeast glucan and immunotherapy of infectious diseases. Front Biol (1979) 48:533-47.

107. Cook JA, Holbrook TW, Parker BW. Visceral leishmaniasis in mice: protective effect of glucan. J Reticuloendothel Soc (1980) 27(6):567-73.

108. Cook JA, Holbrook TW, Dougherty WJ. Protective effect of glucan against visceral leishmaniasis in hamsters. Infect Immun (1982) 37(3):1261-9.

109. Jarecki-Black JC, Glassman AB, James ER. Adoptive transfer of vaccine-induced resistance to Leishmania donovani. Am J Trop Med Hyg (1985) 34(6):1095-7. doi:10.4269/ajtmh.1985.34.1095

110. Holbrook TW, Cook JA. Immunization of mice against Leishmania donovani by subcutaneous injections of dead promastigotes. Am J Trop Med Hyg (1983) 32(1):51-3. doi:10.4269/ajtmh.1983.32.51

111. Al Tuwaijri AS, Mahmoud AA, Al Mofleh IA, Al Khuwaitir SA. Effect of glucan on Leishmania major infection in BALB/c mice. J Med Microbiol (1987) 23(4):363-5. doi:10.1099/00222615-23-4-363

112. Brown GD, Taylor PR, Reid DM, Willment JA, Williams DL, MartinezPomares L, et al. Dectin-1 is a major beta-glucan receptor on macrophages. J Exp Med (2002) 196(3):407-12. doi:10.1084/jem.20020470

113. Yokota K, Takashima A, Bergstresser PR, Ariizumi K. Identification of a human homologue of the dendritic cell-associated C-type lectin-1, dectin-1. Gene (2001) 272(1-2):51-60. doi:10.1016/S0378-1119(01)00528-5

114. Brown GD. Dectin-1: a signalling non-TLR pattern-recognition receptor. Nat Rev Immunol (2006) 6(1):33-43. doi:10.1038/nri1745

115. Upchurch K, Oh S, Joo H. Dectin-1 in the control of Th2-type T cell responses. Receptors Clin Investig (2016) 3(1):e1094. doi:10.14800/rci.1094

116. Grunebach F, Weck MM, Reichert J, Brossart P. Molecular and functional characterization of human Dectin-1. Exp Hematol (2002) 30(11):1309-15. doi:10.1016/S0301-472X(02)00928-1

117. Meyer-Wentrup F, Benitez-Ribas D, Tacken PJ, Punt CJ, Figdor CG, de Vries IJ, et al. Targeting DCIR on human plasmacytoid dendritic cells results in antigen presentation and inhibits IFN-alpha production. Blood (2008) 111(8):4245-53. doi:10.1182/blood-2007-03-081398

118. Joo H, Upchurch K, Zhang W, Ni L, Li D, Xue Y, et al. Opposing roles of Dectin-1 expressed on human plasmacytoid dendritic cells and myeloid dendritic cells in Th2 polarization. JImmunol (2015) 195(4):1723-31. doi:10.4049/jimmunol.1402276

119. Mirkovich AM, Galelli A, Allison AC, Modabber FZ. Increased myelopoiesis during Leishmania major infection in mice: generation of 'safe targets', a possible way to evade the effector immune mechanism. Clin Exp Immunol (1986) 64(1):1-7.

120. Cotterell SE, Engwerda CR, Kaye PM. Leishmania donovani infection of bone marrow stromal macrophages selectively enhances myelopoiesis, by a mechanism involving GM-CSF and TNF-alpha. Blood (2000) 95(5): $1642-51$.

121. Skrzypek F, Cenci E, Pietrella D, Rachini A, Bistoni F, Vecchiarelli A. Dectin-1 is required for human dendritic cells to initiate immune response to Candida albicans through Syk activation. Microbes Infect (2009) 11(6-7):661-70. doi:10.1016/j.micinf.2009.03.010

122. Kim HS, Park KH, Lee HK, Kim JS, Kim YG, Lee JH, et al. Curdlan activates dendritic cells through dectin-1 and toll-like receptor 4 signaling. Int Immunopharmacol (2016) 39:71-8. doi:10.1016/j.intimp.2016.07.013

123. Zhao Y, Chu X, Chen J, Wang Y, Gao S, Jiang Y, et al. Dectin-1-activated dendritic cells trigger potent antitumour immunity through the induction of Th9 cells. Nat Commun (2016) 7:12368. doi:10.1038/ncomms12368

124. Herre J, Marshall AS, Caron E, Edwards AD, Williams DL, Schweighoffer E, et al. Dectin-1 uses novel mechanisms for yeast phagocytosis in macrophages. Blood (2004) 104(13):4038-45. doi:10.1182/blood-2004-03-1140

125. Menon JN, Bretscher PA. Parasite dose determines the Th1/Th2 nature of the response to Leishmania major independently of infection route and 
strain of host or parasite. Eur J Immunol (1998) 28(12):4020-8. doi:10.1002/ (SICI)1521-4141(199812)28:12<4020:AID-IMMU4020>3.0.CO;2-3

126. Maillard I, Launois $\mathrm{P}$, Himmelrich $\mathrm{H}$, Acha-Orbea H, Diggelmann H, Locksley RM, et al. Functional plasticity of the LACK-reactive Vbeta4Valpha8 CD4(+) T cells normally producing the early IL-4 instructing Th2 cell development and susceptibility to Leishmania major in BALB/c mice. Eur J Immunol (2001) 31(4):1288-96. doi:10.1002/1521-4141(200104)31:4<1288: AID-IMMU1288 $>3.0$. CO;2-8

127. Yamakami K, Akao S, Tadakuma T, Nitta Y, Miyazaki J, Yoshizawa N. Administration of plasmids expressing interleukin-4 and interleukin-10 causes $\mathrm{BALB} / \mathrm{c}$ mice to induce a Thelper 2-type response despite the expected $\mathrm{T}$ helper 1-type response with a low-dose infection of Leishmania major. Immunology (2002) 105(4):515-23. doi:10.1046/j.1365-2567.2002.01394.x

128. Aseffa A, Gumy A, Launois P, MacDonald HR, Louis JA, Tacchini-Cottier F. The early IL-4 response to Leishmania major and the resulting Th2 cell maturation steering progressive disease in $\mathrm{BALB} / \mathrm{c}$ mice are subject to the control of regulatory CD4+CD25+ T cells. JImmunol (2002) 169(6):3232-41. doi:10.4049/jimmunol.169.6.3232

129. Radwanska M, Cutler AJ, Hoving JC, Magez S, Holscher C, Bohms A, et al. Deletion of IL-4Ralpha on CD4 T cells renders BALB/c mice resistant to Leishmania major infection. PLoS Pathog (2007) 3(5):e68. doi:10.1371/ journal.ppat.0030068

130. Sadick MD, Heinzel FP, Holaday BJ, Pu RT, Dawkins RS, Locksley RM. Cure of murine leishmaniasis with anti-interleukin 4 monoclonal antibody. Evidence for a T cell-dependent, interferon gamma-independent mechanism. J Exp Med (1990) 171(1):115-27. doi:10.1084/jem.171.1.115

131. Mohrs M, Holscher C, Brombacher F. Interleukin-4 receptor alpha-deficient $\mathrm{BALB} / \mathrm{c}$ mice show an unimpaired $\mathrm{T}$ helper 2 polarization in response to Leishmania major infection. Infect Immun (2000) 68(4):1773-80. doi:10.1128/ IAI.68.4.1773-1780.2000

132. Eyerich K, Dimartino V, Cavani A. IL-17 and IL-22 in immunity: driving protection and pathology. Eur J Immunol (2017) 47(4):607-14. doi:10.1002/ eji.201646723

133. Banerjee A, Bhattacharya P, Joshi AB, Ismail N, Dey R, Nakhasi HL. Role of pro-inflammatory cytokine IL-17 in Leishmania pathogenesis and in protective immunity by Leishmania vaccines. Cell Immunol (2016) 309:37-41. doi:10.1016/j.cellimm.2016.07.004

134. Wu W, Huang L, Mendez S. A live Leishmania major vaccine containing CpG motifs induces the de novo generation of Th17 cells in C57BL/6 mice. Eur J Immunol (2016) 40(9):2517-27. doi:10.1002/eji.201040484

135. Dominguez-Bernal G, Horcajo P, Orden JA, De La Fuente R, Herrero-Gil A, Ordonez-Gutierrez L, et al. Mitigating an undesirable immune response of inherent susceptibility to cutaneous leishmaniosis in a mouse model: the role of the pathoantigenic HISA70 DNA vaccine. Vet Res (2012) 43:59. doi:10.1186/1297-9716-43-59

136. Hezarjaribi HZ, Ghaffarifar F, Dalimi A, Sharifi Z, Jorjani O. Effect of IL-22 on DNA vaccine encoding LACK gene of Leishmania major in BALB/c mice. Exp Parasitol (2013) 134(3):341-8. doi:10.1016/j.exppara.2013.03.012

137. Sacks DL. Vaccines against tropical parasitic diseases: a persisting answer to a persisting problem. Nat Immunol (2014) 15(5):403-5. doi:10.1038/ ni. 2853

138. Khamesipour A, Dowlati Y, Asilian A, Hashemi-Fesharki R, Javadi A, Noazin S, et al. Leishmanization: use of an old method for evaluation of candidate vaccines against leishmaniasis. Vaccine (2005) 23(28):3642-8. doi:10.1016/j. vaccine.2005.02.015

139. Ritter U, Korner H. Divergent expression of inflammatory dermal chemokines in cutaneous leishmaniasis. Parasite Immunol (2002) 24(6):295-301. doi:10.1046/j.1365-3024.2002.00467.x

Conflict of Interest Statement: The authors declare that the research was conducted in the absence of any commercial or financial relationships that could be construed as a potential conflict of interest.

Copyright $\odot 2018$ Zimara, Chanyalew, Aseffa, van Zandbergen, Lepenies, Schmid, Weiss, Rascle, Wege, Jantsch, Schatz, Brown and Ritter. This is an open-access article distributed under the terms of the Creative Commons Attribution License (CC BY). The use, distribution or reproduction in other forums is permitted, provided the original author(s) and the copyright owner are credited and that the original publication in this journal is cited, in accordance with accepted academic practice. No use, distribution or reproduction is permitted which does not comply with these terms. 